$$
\text { PNL-2627, UC-64 }
$$

TECHNICAL REPORT 7?OI-2

\title{
CONCEPTUALIZATIONS FOR CLEANING \\ OTEC HEAT EXCHANGERS
}

$$
\text { by }
$$

Mark S. Rice, Dahlia Hagel,

and Andrew F. Conn

September 1978

\section{HYDRONAUTICS, incorporated research in hydrodynamics}

Research, consulfing, and advanced engineering in the fields of MAVAL and INDUSTRIAL HYDRODYHAMICS. Offices and Laboratory in the Washinglon, D. C., area: Pindell School Road, Howard County, Laurel, Md. 


\title{
33679000490229
}

HYDRONAUTICS, INCORPORATED

PNL-2627, UC-64

TECHNICAL REPORT 7?01-2

\author{
CONCEPTUALIZATIONS FOR CIEANING \\ OTEC HEAT EXCHANGERS \\ by \\ Mark S. Rice, Dahlia Hagel, \\ and Andrew F. Conn \\ September 1978
}

\begin{abstract}
Prepared for
Pacific Northwest Laboratory

Under Agreement No. B-31927-A-L
\end{abstract}
Pacific Northwest Laboratory
Richland, Washington 99352
Operated for
U. S. Department of Energy
by

Battelle Memorial Institute 
HYDRONAUTICS, Incorporated

$$
-i-
$$

TABLE OF CONTENTS

Page

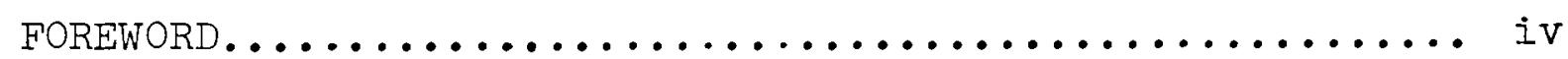

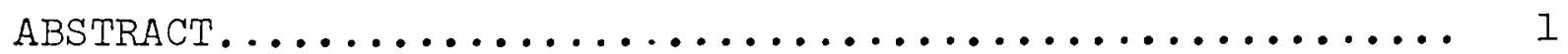

I. SCOPE OF THE PROGRAM...................... 3

II. SUMMARY OF TASK $I$ RESULTS.................. 5

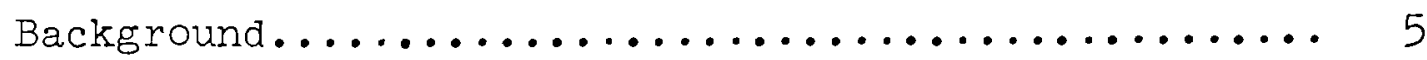

Review of the Fouling Control Methods........... 7

III. CONCEPTUALIZATIONS OF FOULING CONTROL METHODS FOR

VARIOUS HEAT EXCHANGER DESIGNS............. 15

A. Fouling Control in Smooth Bore Tubes with

Seawater Inside..................... 17

B. Fouling Control in Internally Enhanced Tubes with Seawater Inside...................... 33

C. Fouling Control in Large Diameter Tubes with Seawater Outside ("Trombone" Design)......... 40

D. Fouling Control in Plate-Fin or Extended.

Surface Heat Exchangers................. 47

E. Fouling Control in Open-Cycle Designs......... 50

IV. CONCLUSIONS AND RECOMMENDATIONS............. 52

A. Conclusions......................... 52

B. Recommendations for Further Research and

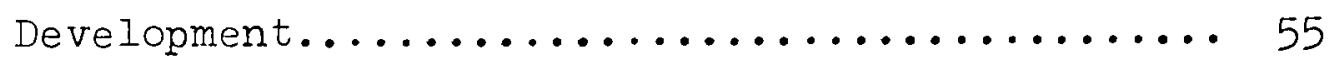

APPENDIX A - HEAT EXCHANGER DESIGN CONCEPTS.......... 58

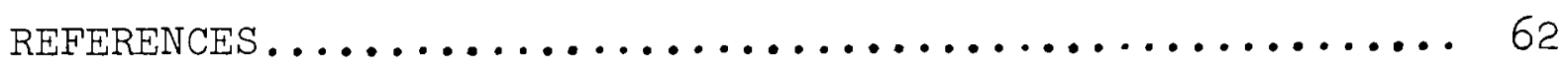


HYDRONAUTICS, Incorporated

$-i i-$

LIST OF FIGURES

Page

Figure 1 - Recirculating Rubber Balls .......... 21

Figure 2 - Synchronized Injector and Collector Concept. . 22

Figure 3 - Flow Driven Brushes........... 24,26

Figure 4 - Flow Driven Brushes. . . . ..... 27,29

Figure 5 - A Water Treatment System Using Onsite Electrolytic Generation of Sodium Hypochlorite. . . . . 31

Figure 6 - An Ozone Water Treatment System. . . . . 35

Figure 7 -Ultraviolet Water Treatment. . . . . . 36

Figure 8 - Ultrasonic Biofouling Prevention . . . . . 39

Figure 9 - A Chemical Cleaning System with Recirculation Capability ............ . 41

Figure 10 - A Once-Through Foamed Chemical Cleaning System 42

Figure lla - Large Diameter Tube and Shell Heat Exchanger. 45

Figure llb - Water Jet Cleaning. . . . . . . . . . 46

Figure 12 - A Plate-Fin Heat Exchanger. . . . . . . 49 
HYDRONAUTICS, Incorporated

$$
\text { -iii- }
$$

\section{LIST OF TABLES}

Page

Table 1 - Compatibility of Methods with Various OTEC Heat Exchanger Design and Materials . . . 16

Table 2 - Comparison of Estimated Costs for Water Treatment in a $368 \mathrm{MW}$ Baseline OTEC Power Plant............. 18

Table 3 - Mechanical Cleaning Systems-Preliminary Cost Estimates for a 368 MWe OTEC Plant . . 19 
HYDRONAUTICS, Incorporated

$$
-i v-
$$

FOREWORD

This report was prepared by HYDRONAUTICS, Incorporated, Laurel, Maryland, under Battelle Pacific Northwest Laboratories' Contract Number B-31927-A-L. This contract was initiated as part of the Biofouling and Corrosion Project which is being administered by Battelle PNL, under the management of Dr. Lyle D. Perrigo, for the U. S. Energy Research and Development Administration.

The report is a summary of the work performed under the second task, and thus completes the work scheduled under this Contract.

The valuable discussions and suggestions throughout this task, from Dr. Perrigo and Dr. George A. Jensen, Senior Project Engineer, Biofouling and Corrosion Project, are gratefully acknowledged.

We also thank Dr. T. R. Sundaram for his valuable guidance in the preparation of this report, and Messrs. Vernon $J$. Laverty, Steven H. Cohen, and Stephen J. Daugard for their many ideas and constructive critiques. One of the authors, Mark S. Rice, is now with SEACO, Incorporated in Kailua, Hawaii. 
HYDRONAUTICS, Incorporated

\section{ABSTRACT}

A critical operating aspect of Ocean Thermal Energy Conversion (OTEC) plants is the maintenance of clean surfaces on the seawater-side of the heat exchangers. The objective of this program was to assess the state of the art of biofouling control techniques and to evaluate the potential of these existing methods for solving the biofouling problems in the OTEC system.

The first task of the program involved an in-depth review and discussion of various fouling control methods including water treatment, surface conditioning and cleaning techniques. The methods considered applicable to OTEC were identified (1).

This volume summarizes the second task of the program. The compatibility of the various cleaning and fouling control techniques with the different proposed heat exchanger designs and materials are discussed. Also provided are conceptual illustrations for adapting and incorporating the methods into an OTEC power plant.

These conceptual designs suggest means for overcoming some of the shortcomings of the techniques which are considered suitable, however, detailed designs of the modified systems are beyond the scope of this report.

Chlorination, chemical cleaning, Amertap recirculating sponge rubber balls, and MAN flow-driven brushes are the methods considered applicable for tubular heat exchangers with seawater inside the tubes. Water jets are suggested for the open-cycle and the "trombone" (Applied Physics Laboratory) heat exchanger designs. Although none of the methods are immediately applicable 
HYDRONAUTICS, Incorporated

$$
-2-
$$

to OTEC in their present configuration, in several cases only minor developmental efforts should produce designs which can satisfy the stringent OTEC cleanliness requirements. Further research and development appear warranted for a number of other methods which indicate promise for long-range applicability. Specific recommendations are included in the final chapter of this report. 
HYDRONAUTICS, Incorporated

I. SCOPE OF THE PROGRAM

Ocean Thermal Energy Conversion (OTEC) is crucially dependent upon the maintenance of design heat-transfer coefficients if effective operation is to be achieved. Of specific interest is that portion of the heat transfer resistance which results from the adherence of both organic and inorganic matter to the seawater side of the heat transfer surfaces. This adhering matter may be biological organisms, chemical precipitates, debris carried by the seawater, or corrosion products formed at the seawater/heat-exchanger interface.

Under the first task of this program (1), a comprehensive survey was undertaken to identify those chemical and/or mechanical methods that might be applicable to cleaning OTEC heat exchangers. Although numerous methods were identified, it was difficult to scale their usage up to OTEC conditions due to the vast differences between OTEC and the conventional applications. Based upon the findings of the first task, the present effort involved conducting a conceptual study of mechanical and chemical methods that are potentially suitable for use in cleaning heat exchangers of the types that are under consideration for OTEC power plants.

The conceptualizations discussed in this volume reflect the present state-of-the-art for the various surface treatment, water treatment, and cleaning methods. Also included are suggestions for overcoming some of the problems and shortcomings of these systems when incorporated and adapted into an OTEC plant. However, before any of these necessarily general system 
HYDRONAUTICS, Incorporated

$$
-4-
$$

concepts can be reduced to detailed engineering designs, answers must be obtained to the major questions which affect the selection and operation of an OTEC heat exchanger cleaning system:

a. What will be the rate of fouling growth in the heat exchangers, initially, and after a possible "island effect" is established?

b. What will be the minimum effective level of treatment of a given control or cleaning method in order to maintain the required surface cleanliness?

*An OTEC power plant may act as an artificial island, wherein accelerated biofouling couid be experienced. 
HYDRONAUTICS, Incorporated

\section{$-5-$ \\ II. SUMMARY OF TASK 1 RESULTS}

Background

During the first task of this investigation, a systematic study was made of the methods currently in commercial use to control fouling in heat exchangers. The results of this study, including detailed assessments of each method identified as being even remotely applicable to OTEC, are contained in the Task 1 report (1). Brief reviews of these methods are provided here for reference only.

The methods currently available for biofouling control can be divided into the following three categories:

1. Surface treatment methods which are applied to the seawater/heat exchanger interfaces to prevent the adhesion of biofouling organisms,

2. Water treatment methods, which are chemical or optical in nature and render microorganisms incapable of active fouling, and

3. Chemical or mechanical cleaning methods, which involve either utilization of chemicals or mechanical scrubbing to remove fouling layers.

A fourth category, that is not a control method, per se, involves preventive design, either through fluid dynamics or material properties that are designed into the heat exchanger. Certain copper alloys, such as CA $706^{*}$, and fouling resistant plastics which are currently under development may provide considerable protection against macrofouling; however, their

*A 90/10 Cu-N1 alloy. 
HYDRONAUTICS, Incorporated

$$
-6-
$$

effectiveness against microfouling, which is the chief concern in OTEC, has not been established.

Within the three categories the following methods were investigated:

Surface Treatment Methods

- Low Surface Energy Coatings

- Fouling Resistant Materials for Heat Exchanger Construction

Water Treatment Methods

- Chlorination

- Deaeration

- Debris Screening

- Heat Treatment

- Ozonation

- Ultrasonic Biofouling Prevention

- Ultraviolet Treatment

Chemical or Mechanical Cleaning Methods

- Air or Water Driven Plugs or Scrapers

- Chemical Cleaning

- Flow Driven Brushes

- Helically Twisted Inserts

- Recirculating Rubber Balls

- Slurry Cleaning

- Water Jet Cleaning 
HYDRONAUTICS, Incorporated

Review of the Fouling Control Methods

In the earlier work of the present program, it was found that many existing methods cannot be scaled up directly to meet OTEC requirements due to excessive head losses, cost, and environmental limitations. However, it was necessary to undertake preliminary calculations to determine a given method's applicability to OTEC. General descriptions of each fouling control method are given on the following pages. The reader is encouraged to refer to Reference $l$ if detailed information is desired.

\section{Low Surface Energy Coatings}

The concept behind this technique is the modification of the surface characteristics of the heat exchanger so as to discourage the adherence of proteinacious films to the wall (these are believed to be a prerequisite for the development of microbial slimes). A method was developed for depositing a monomolecular layer of a fluoropolymer, with a surface energy of 25-30 dyne $/ \mathrm{cm}$ onto a metal surface. This method is in its early developmental stages and although it retards fouling appearance somewhat, the life span of the coating is currently limited to $1-2$ weeks.

\section{Fouling Resistant Materials for Heat Exchanger Con- struction}

This involves the construction of heat exchangers from fouling resistant alloys such as CA 706 or the use of extrudable thermoplastic materials currently under development. The plastics have the desired low surface energy, but may require 
HYDRONAUTICS, Incorporated

copper or other additives for enhancement of heat transfer coefficients.

\section{Chlorination}

On-site electrolytic generation of sodium hypochlorite from seawater is an established water treatment method in coastal power plants. These use shock treatment at 2 to $10 \mathrm{ppm}$, or a continuous dosage in the range of 0.2 to $1 \mathrm{ppm}$ to discourage macrofouling growth. Dosages as low as $0.02 \mathrm{ppm}$ have also been reported, however, the inadequacy of measuring techniques would render these difficult to control. The minimum dosage and optimum treatment schedule for control of microbial slimes have yet to be established. Another question requiring further research is how effectively can microbial slimes, which are already attached to the heat exchanger walls, be removed by sodium hypochlorite. See further discussion in section III.A.

\section{Deaeration}

Seawater can be deaerated or deoxygenated through several chemical or physical processes, thus preventing the growth and multiplication of aerobic organisms. However, the cost of deaerating the tremendous volumes of water involved in an OTEC plant is likely to be intolerably high, especially in a closed cycle OTEC. Furthermore, it is not known what percentage of the microbial foulants in the OTEC environment will be anaerobic and therefore unaffected by this technique.

\section{Debris Screening}

None of the existing mechanical heat exchanger cleaning methods, such as the M.A.N. or the Amertap systems, will 
HYDRONAUTICS, Incorporated

operate without removal of large floating debris and marine organisms. Furthermore, this debris can significantly shorten the heat exchanger life by damaging and/or blocking the tubes. For these reasons, although it is not classified as a biofouling control method, some form of debris screening must be included at the seawater intakes of any OTEC plant. Screen designs should provide for minimal head losses and low intake velocities to protect marine life.

\section{Heat Treatment}

Steam and/or heated water $\left(150^{\circ}-200^{\circ} \mathrm{F}\right)$ are used in coastal power plants to prevent and destroy macrofouling in the inlet ducts and heat exchanger water boxes. Although useful in these conventional plants, where hot water and steam are abundant and can easily be redirected to the inlet ducts, this method is not practical for use in OTEC due to the large volumes, the absence of high temperature water, and the intolerably high cost that would be required to produce such temperatures.

\section{Ozonation}

Ozone or a combination of ozone and ultraviolet radiation are very effective water treatment methods, with almost no permanent residual toxicity. Ozone can be generated on-site from air or oxygen. However, the power requirements exceed those for sodium hypochlorite generation by a factor of six or seven. Thus, unless new ozone generation techniques, now under development, can greatly reduce the power costs, this method will not be feasible for OTEC. Although combining ozone and UV may lower the required ozone concentrations, the current 
HYDRONAUTICS, Incorporated

equipment, installation and operating costs are still too high to be competitive with chlorination.

8. Ultrasonic Biofouling Prevention

Although the high intensity ultrasonic energy now used to clean and degrease components is not practical for OTEC, there have been qualitative demonstrations of macrofouling prevention at somewhat lower power levels. If a similar prevention of microfouling can be shown, ultrasonics might be practical for some OTEC designs. Further study of low level ultrasonics to verify these effects seems warranted.

9. Ultraviolet Treatment

The UV wavelength of $2537 \AA$ A causes disruptive resonance in DNA and protein molecules, thus destroying living tissue, at adequate intensity and exposure times. UV is commonly used for wastewater treatment, alone and in combination with ozone. However, as it has not been used by power plants, its performance in controliing microfouling in seawater heat exchangers is uriproven.

10. Air or Water Driven Plugs or Scrapers

This method requires draining of the heat exchanger and its water boxes so that personnel can "shoot" the tubes with one of a variety of projectiles. The method is labor intensive and is not suitable in its state-of-the-art form for OTEC. However, automation of the method to allow on-line operation might render it applicable. 
HYDRONAUTICS, Incorporated

\section{Chemical Cleaning}

This method requires shutdown and isolation of the heat exchanger module to be cleaned, with subsequent foaming, recirculating, soaking, or purging of an acidic or basic cleaning compound. The cleaning compounds dissolve, decompose and/or loosen the bonds between the fouling layers and the heat exchanger surfaces. To complete the operation the heat exchanger is drained and rinsed. Chemical cleaning is one of the oldest methods used in conventional power plants, and it is applied when fouling accumulation becomes excessive (approximately every 2 years).

The main advantages are: ability to remove even the heaviest fouling down to base metal, and applicability to any heat exchanger geometry. Although the effectiveness of certain cleaning compounds in achieving the desired cleanliness is known, the economics and cost effectiveness of the overall process in an OTEC application needs further study. To avoid adverse environmental effects and waste of large amounts of chemicals, the two potentially applicable cleaning modes for OTEC would be: foaming with subsequent collection and treatment of the effluents, or recirculating the cleaning solution with facilities for filtering and restoring the strength of the chemicals.

To incorporate a chemical cleaning system into an OTEC operation, the following design features are required: further modularization of heat exchangers with sufficient valving to allow isolation of these submodules, to minimize overall shutdown times; a piping network to connect all submodules to the 
HYDRONAUTICS, Incorporated

storage and treatment facilities; proper venting capabilities, and large, acid/base resistant storage and treatment tanks.

Since chemical cleaning involves removal of a certain amount of base metal, causing or exposing pin-hole leaks and reducing tube life, it is not recommended for frequent use, unless with inert alloys such as titanium or AL-6X stainless steel.

12. Flow-Driven Brushes (The American M.A.N. System)

One of two automated methods for cleaning internal tube surfaces, the M.A.N. system uses periodic flow reversal to drive brushes through the heat exchanger tubes. Preliminary estimates suggest that a modified concept of this method could be cost effective; however, erosive/corrosive effects of the brushes on aluminum surfaces are unknown. Furthermore, the M.A.N. system requires incorporating flow reversal features in the heat exchanger designs. The problems and costs associated with this requirement need to be thoroughly investigated (see also Section III.A).

\section{Helically Twisted Inserts}

This technique, now in early development, would utilize a twisted thermoplastic tape insert anchored at the upstream tube sheet. The inventor (12) states that the freely rotating inserts may serve the dual purpose of heat transfer enhancement and biofouling control through periodic interruption of the thermal and fluid dynamic boundary layers. The on-going studies of this method must determine whether head losses from such inserts will be offset by the aforementioned possible gains. 
HYDRONAUTICS, Incorporated

14. Recirculating Rubber Balls (The Amertap System)

This method circulates sponge rubber balls which wipe the inside surface of the heat exchanger tubes. Although Amertap has had a large amount of commercial power plant experience, the vast differences between OTEC and conventional power generation prevent a simple scaling-up of this method. Key problems include the need for development of low head-loss debris and ball-collecting screens; possible erosion/corrosion enhancement by the balls; and the complexity of automated ball sorting and rejection mechanisms at the scale required for OTEC (see also Section III.A).

15. Slurry Cleaning

The method is not an established cleaning technique, but is discussed here since it shows potential for future application to OTEC. Diatomaceous earth slurries vere studied for removing films from and decontamination of metal surfaces in nuclear reactors (18, 19): however, the available information is inadequate to permit evaluation for OTEC applications. Flyash in the intake cooling water of some power plants apparently provided a mild abrasive action which minimized fouling. Thus, if a readily available, inexpensive, nonpolluting slurry material could be developed, this could serve as an on-line, once-through cleaning media for OTEC heat exchangers.

In comparison to chemical cleaning methods, slurry cleaning offers the potential advantages of materials which are safe and easy to store; elimination of recirculation and recovery 
HYDRONAUTICS, Incorporated

components, and fresh water rinses. The mild abrasive action of slurries should remove all anticipated OTEC microfouling with minimal tube wall erosion, and would be applicable to most heat exchanger geometries without requiring shutdown.

The possible disadvantages include large storage facilities, unless on-site "mining" is developed; clogging of tubes, especially those with heat transfer enhancements such as flutes or grooves; and tube erosion.

The basic problem with this method is that no slurry material has yet been identified which meets all of the necessary requirements. The cost of diatomaceous earth at $\$ 50$ to $\$ 100$ per ton is high, and the entire current USA yearly production of diatomaceous earth (about 750,000 tons) would be needed to make a 1 percent slurry for a 24-hour cycle once-through cleaning of a 100-MW OTEC power plant. Thus, unless an inexpensive recovery and recirculation procedure is developed, or a material such as sand is found to be acceptable, there does not seem to be near term applicability of slurry cleaning for OTEC heat exchangers.

16. Water Jet Cleaning

In recent years this method has become widely used for the cleaning of the water side of marine boilers. If water jets are used for cleaning OTEC heat exchangers, their practical application would only be in large, multijet arrays which could be rapidly and automatically moved about the tube bundles. Questions of power required per unit area to remove microfouling, and the possibility of tube erosion must also be answered. 
HYDRONAUTICS, Incorporated

III. CONCEPTUALIZATIONS OF FOULING CONTROL METHODS FOR VARIOUS HEAT EXCHANGER DESIGNS

A wide range of heat exchanger designs and construction materials have been proposed for OrEC. Candidate materials include titanium, aluminum, copper-nickel, AL-6X stainless steel and plastics. Since the compatibility of a cleaning method with a particular heat exchanger is determined by both its design and material of construction, a large matrix of design/material combinations must be evaluated. To aid in this evaluation the heat exchanger designs have been grouped as:

- Smooth bore tube and shell designs with seawater inside the tubes,

- Internally or externally enhanced-surface tube and shell designs with seawater inside the tubes,

- Large diameter tube and shell designs with seawater on the outside of the tubes ("trombone" design),

- Plate-fin or extended surface designs, and

- Falling film plates or other plate-like open-cycle concepts.

Cleaning methods for each of these five categories are discussed below, with consideration given to candidate materials in each discussion. In Table 1 , a ranking number indicates the compatibility of a given fouling control technique with a particular heat exchanger design that is fabricated from a specific material. Brief discussion of the configurations of the five proposed heat exchanger types are provided in Appendix A. 
TABLE 1

COMPATIBILITY OF METHODS WITH VARIOUS OTEC HEAT EXCHANGER DESIGN AND MATERIALS

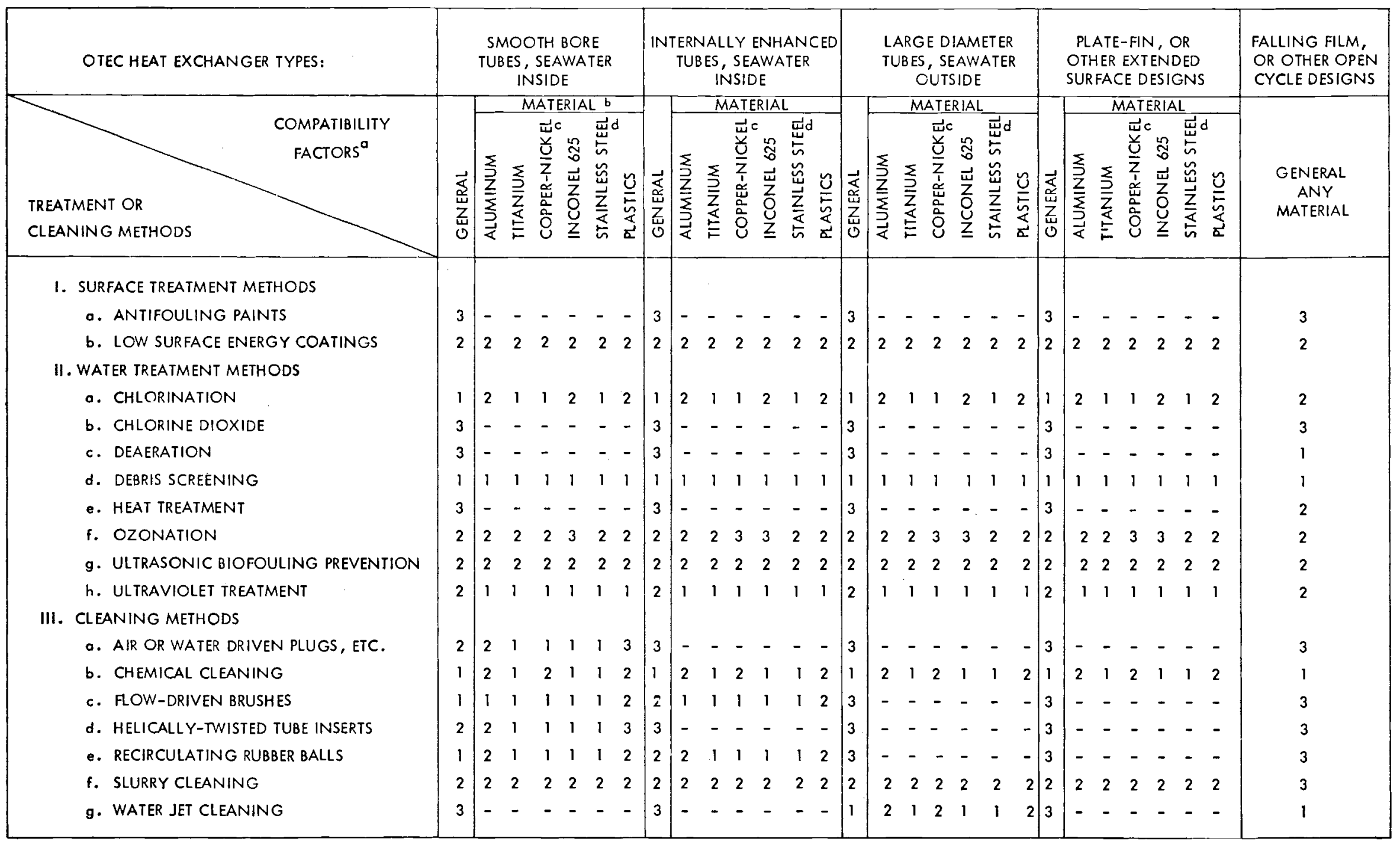

a. The "GENERAL" factor is an overall rating, based on cost, practicality, and geometry;

The RATING NUMBERS are: 1: Well Suited 2: Requires further $R \& D$ to determine compatibility, 3: Not Suited, - : Not Applicable

b. Material ratings are independent from the "GENERAL" rating.

c. Copper nickel olloy CA706 ( $90 / 10$ Cu-Ni)

d. Stainless steel alloy AL $-6 \mathrm{X}$ 
HYDRONAUTICS, Incorporated

A. Fouling Control in Smooth Bore Tubes with Seawater Inside

Smooth bore tube and shell designs with seawater flowing internally are common in coastal power stations. Experience in power plant biofouling control has been limited to chlorination, the Amertap system, the M.A.N. system, chemical cleaning, and projectile "shooting." As indicated in Table l, several other techniques may present long range potential applicability. Tables 2 and 3 show cost estimates for several of these methods (1). These costs are preliminary and the assumptions and approximations used to derive these costs should be considered before attempting to use and compare the figures in these tables.

The three methods which are considered suitable for short term incorporation in this type of OTEC heat exchanger are:

- The Amertap System

- The M.A.N. System, and

- Chlorination.

Certain combinations of these three methods may also be considered.

The manual tube shooting method is considered to be impractical for OTEC. Since the tolerable fouling factor in an OTEC power plant is minimal ( $\left.R<0.0005 \mathrm{hr}-\mathrm{ft}^{2}-{ }^{\circ} \mathrm{F} / \mathrm{BTU}\right)$, and relatively frequent applications of any cleaning method will be required, it seems unlikely that chemical cleaning will be a competitive method for this type of heat exchanger when compared with the methods discussed below. Similarly, high cost and lack of experience in power plants rule out further consideration of ozonation, ultrasonic prevention and UV-treatment. 
Table 2

COMPARISON OF ESTIMATED COSTS FOR WATER TREATMENT IN A 368 MW BASELINE OTEC POWER PLANTa

\begin{tabular}{|c|c|c|c|c|c|c|c|}
\hline \multirow{2}{*}{\multicolumn{2}{|c|}{$\begin{array}{ll}\text { Cost } & \text { System } \\
\text { Breakdown } & \end{array}$}} & \multicolumn{2}{|c|}{$\begin{array}{c}\text { Ozonationc } \\
(1 \mathrm{ppm} \text { continuous }) \\
\end{array}$} & \multicolumn{2}{|c|}{$\begin{array}{c}\text { Electrolytic } \\
\text { Hypochlorination }\end{array}$} & \multirow{2}{*}{$\begin{array}{l}\text { Ultrasonic } \\
\text { Biofouling } \\
\text { Prevention }\end{array}$} & \multirow{2}{*}{$\begin{array}{c}\text { Ultraviolet } \\
\text { Water } \\
\text { Treatment }\end{array}$} \\
\hline & & Current & Projected & $1 \mathrm{ppm}$ & $0.2 \mathrm{ppm}$ & & \\
\hline \multicolumn{2}{|c|}{$\begin{array}{l}\text { Initial Capital Cost } \\
\text { in } 1976 \$ 10^{6}\end{array}$} & 1000.0 & 125.0 & 38.0 & 7.6 & $11.0^{\mathrm{h}}$ & 2.3 \\
\hline 焉 & Operating Power (MW) & 659.0 & 232.0 & 87.4 & $17 \cdot 5$ & $11.0^{h}$ & 12.4 \\
\hline \multirow{6}{*}{ 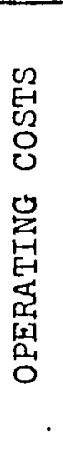 } & \multicolumn{7}{|c|}{$10^{6} \$ /$ Year } \\
\hline & $\begin{array}{l}\text { Ammortization } \\
\text { (over 20 years) }\end{array}$ & 120.0 & 15.0 & 4.6 & 0.9 & 1.3 & 0.2 \\
\hline & $\begin{array}{l}\text { Power Cost } \\
\text { (at } 0.04 \$ / \mathrm{kwhr}\end{array}$ & 230.0 & 81.0 & 30.6 & 6.1 & 3.8 & 4.3 \\
\hline & Materials & A $1 r$ & Air & \multicolumn{2}{|c|}{ Seawater } & - & - \\
\hline & $\begin{array}{l}\text { Maintenance } \\
\text { Replacement Parts }\end{array}$ & \} 30.0 & \} 4.0 & $\begin{array}{l}3.5 \\
3.9\end{array}$ & $\begin{array}{l}0.7 \\
0.8\end{array}$ & $\begin{array}{l}3.7 \\
3.7\end{array}$ & 3.7 \\
\hline & Tota.1 & 380.0 & 100.0 & 42.6 & 8.5 & 1.2 .5 & 8.2 \\
\hline
\end{tabular}

\begin{tabular}{|c|c|c|c|c|c|c|c|}
\hline \multirow{3}{*}{ 总 } & $\$ / G P M / Y r$. & 7.6 & 2.0 & 0.9 & 0.2 & 0.25 & 0.2 \\
\hline & Mills/kwhr & $\mathrm{NA}^{\mathrm{d}}$ & 31.0 & 13.2 & 2.6 & 3.9 & 2.5 \\
\hline & $\begin{array}{l}\text { Milis/kwhr } \\
\text { (cost of p }\end{array}$ & $N A^{d}$ & 58.0 & 3.7 & 0.7 & 2.7 & 1.2 \\
\hline
\end{tabular}

Notes: a. Lockheed baseline deslgn, $368 \mathrm{MW}$ gross output, $280 \mathrm{MW}$ net output.

b. See Reference 1 for detailed discussion of methods and costs.

c. Current system is not applicable due to the high initial cost and impossible

power requirements (2.3 times the net output of the plant).

d. Not applicable (see c above)

e. The effectiveness of this method for biofouling prevention has not been established.

f. An hourly rate of $\$ 10.00$ per hour has been assumed.

B. Based on 20 years plus $7 \%$ yearly interest on bonds.

h. Assuming a power requirement of 5 watts $/ \mathrm{m}^{2}$ at an installed cost of $\$ 1.00 /$ watt. 
Table 3

MECHANICAL CLEANING SYSTEMS-PRELIMINARY COST ESTIMATES FOR A 368 MWe OTEC PLANT ${ }^{a}$

\begin{tabular}{|c|c|c|c|c|}
\hline \multicolumn{2}{|c|}{$\begin{array}{ll}\text { Cost } & \text { System } \\
\text { Breakdown } & \end{array}$} & \begin{tabular}{|c|} 
Amertap \\
Recirculating \\
Rubber Balls
\end{tabular} & $\begin{array}{l}\text { M.A.N.Flow } \\
\text { Driven Brushes }\end{array}$ & $\begin{array}{l}\text { Air or Water } \\
\text { Propelled } \\
\text { Projectiles }\end{array}$ \\
\hline \multicolumn{2}{|c|}{$\begin{array}{l}\text { Initial Capital } \\
\text { Cost, in } 1976, \$ 10^{6}\end{array}$} & 50.0 & $5.6^{e}$ & 0.5 \\
\hline & $\begin{array}{l}\text { Operating Power } \\
\text { Requirement (MW) }\end{array}$ & 8.0 & $0.9^{f}$ & 11.5 \\
\hline \multicolumn{5}{|c|}{$10^{6} \$ /$ Year } \\
\hline \multirow{4}{*}{ 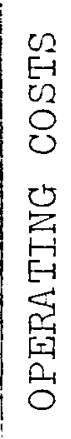 } & $\begin{array}{l}\text { Ammortization } \\
\text { (over } 20 \text { yrs) }\end{array}$ & 6.0 & 0.7 & 0.1 \\
\hline & $\begin{array}{l}\text { Power Cost (at } \\
0.040 \$ / \mathrm{kWh} \text { ) }\end{array}$ & 2.8 & 0.3 & 4.0 \\
\hline & $\begin{array}{l}\text { Maintenance } \\
\text { Parts \& Materi- } \\
\text { als }\end{array}$ & $\begin{array}{l}0.7^{c} \\
0.5^{d}\end{array}$ & $\begin{array}{l}0.7 \\
0.9\end{array}$ & \} \\
\hline & Total & 10.0 & 2.6 & 5.4 \\
\hline
\end{tabular}

\begin{tabular}{|c|c|c|c|c|}
\hline \multirow{3}{*}{ 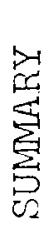 } & $\$ / \mathrm{Yr} / \mathrm{gpm}$ & 0.2 & 0.05 & 0.11 \\
\hline & Mills $/ \mathrm{kWh}^{i}$ & 3.1 & 0.8 & 1.7 \\
\hline & $\begin{array}{l}\text { Mills/kWh (pow- } \\
\text { er cost excluded }\end{array}$ & 2.2 & 0.7 & 0.4 \\
\hline
\end{tabular}

\section{Notes:}

a. Lockheed baseline design, 368 MW gross output, 280 MW net output.

b. See detailed discussions of methods and costs in Reference 1.

c. Assuming semiautomated operation.

d. Number of balls assumed to be $10 \%$ of the number of tubes. Ball replacement assumed once a month.

e. Includes brushes, baskets and installation. Does not include flow reversal equipment and design.

f. Does not include power losses during flow reversal.

g. Labor cost assumed to be $\$ 10.00 /$ hour. Living costs, overhead and benefits not included.

n. Ammortization over 20 years plus $7 \%$ yearly interest on bonds.

i. Including the cost of operating power at $0.040 \$ / \mathrm{kWh}$. 
HYDRONAUTICS, Incorporated

$$
-20-
$$

Amertap System - A conventional Amertap system could be applied to OTEC heat exchangers if these are broken into modules that correspond in size to those found in existing power plants. This concept is shown in Figure 1. The conventional Amertap system consists of ball injection ports in front of the upstream tube sheet and a collection screen beyond the downstream tube sheet. Recirculation of balls, ball counting and ball sizing functions are accomplished by Amertap equipment installed outside of the heat exchanger. Butterfly valves should be provided in each subdivision of the heat exchanger to allow for repairs in the Amertap screens without shutdown of the entire heat exchanger.

Figure 2 illustrates conceptually the modified Amertap system suggested in the TRW and Lockheed proposed baseline designs $(7,8)^{*}$. This concept involves relatively small, funnelshaped ball injectors and collectors. These coarse mesh basket devices would move synchronously over the inlet and outlet tube sheets. This modified system has a number of advantages, the more important of which are the ability to easily vary the cleaning frequency and the reduction of head losses due to the collection screens in the conventional design. Furthermore, the proposed system would utilize much of the off-the-shelf equipment that is marketed by Amertap. Several disadvantages include

* TRW representatives have since indicated that they are reconsidering this modified concept due to the complex design problems which would be involved. However, no alternative designs were proposed. 


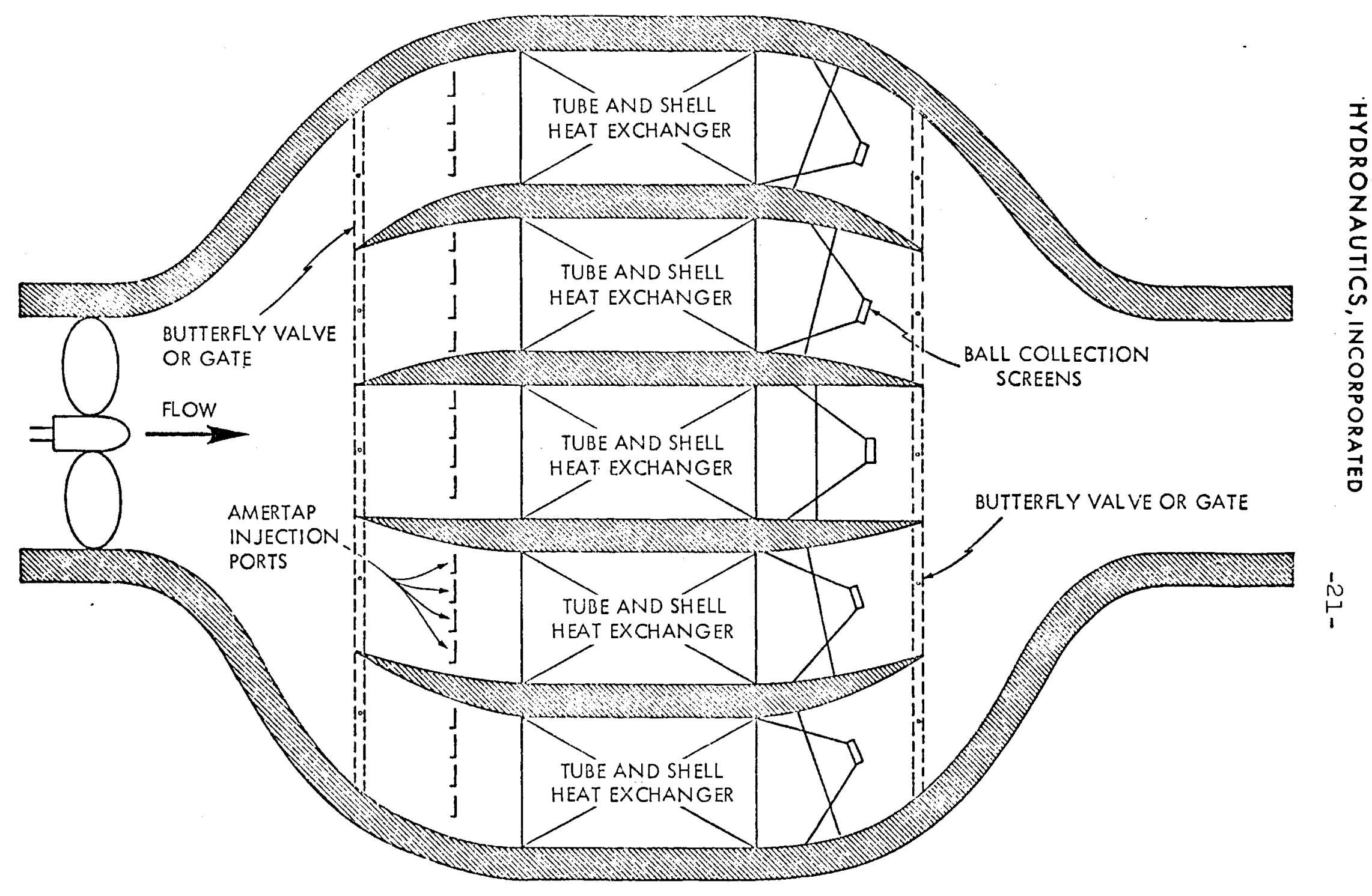

FIGURE 1 - RECIRCULATING RUBBER BALLS: Using a state-of-the-art conceptualization of the Amertap System in a $25 \mathrm{MWe}$ heat exchanger module with five submodules. 


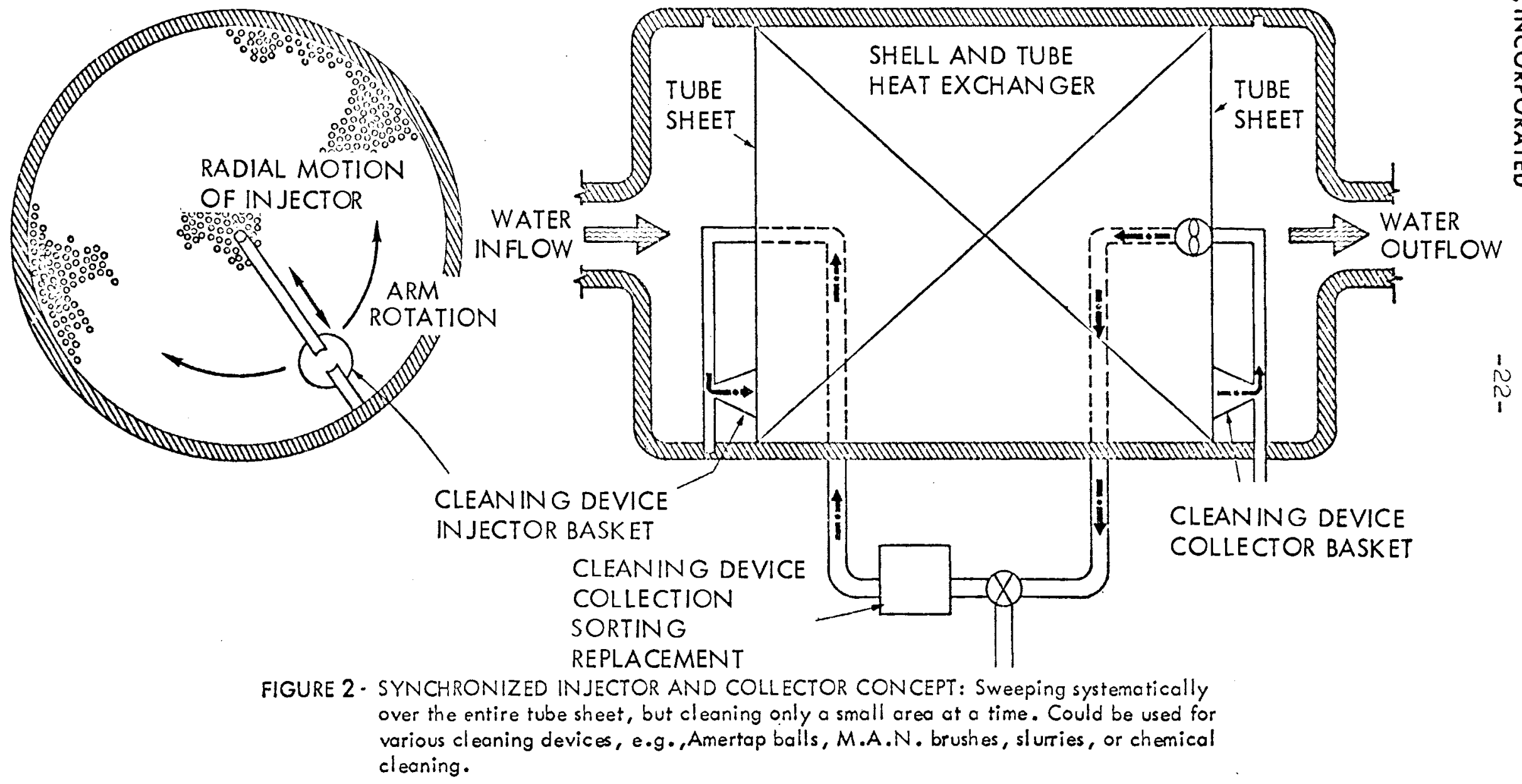


HYDRONAUTICS, Incorporated

the uncertainty about whether adequate cleaning can be achieved by the Amertap balls, the need for a complex indexing system with sensors to insure synchronization, logistics problems of collecting, counting, sorting, and replacing the balls, and unanswered questions regarding the erosive and/or corrosive effects of Amertap balls on aluminum tubes.

Although this "pitch-and-catch" concept was proposed for use with Amertap sponge rubber balls, the concept may also lend itself to slurry cleaning, chemical cleaning, or cleaning using projectiles. An extensive and imaginative design effort is needed to translate this concept into reality.

M.A.N. System - The second candidate system for cleaning internal tube surfaces is the M.A.N. system. As already mentioned, its operation requires periodic flow reversal in the heat exchangers. In large installations, this function is accomplished by modularizing and reversing the flow in each portion of the heat exchanger separately, thus considerably reducing the size and cost of the reverse flow equipment. However, a complex by-pass piping network and valving system is still required.

Figure $3 a$ illustrates a conceptual adaptation of the M.A.N. system to OTEC conditions. To utilize this concept, it would probably be necessary to subdivide a $100 \mathrm{MW}$ plant into about 12 to 16 submodules, instead of the four main modules which have been suggested $(7,8)$. Each of these submodules would then be further subdivided into the two parts as seen in Figure 3a. The normal seawater flow through the two adjacent halves would be in 


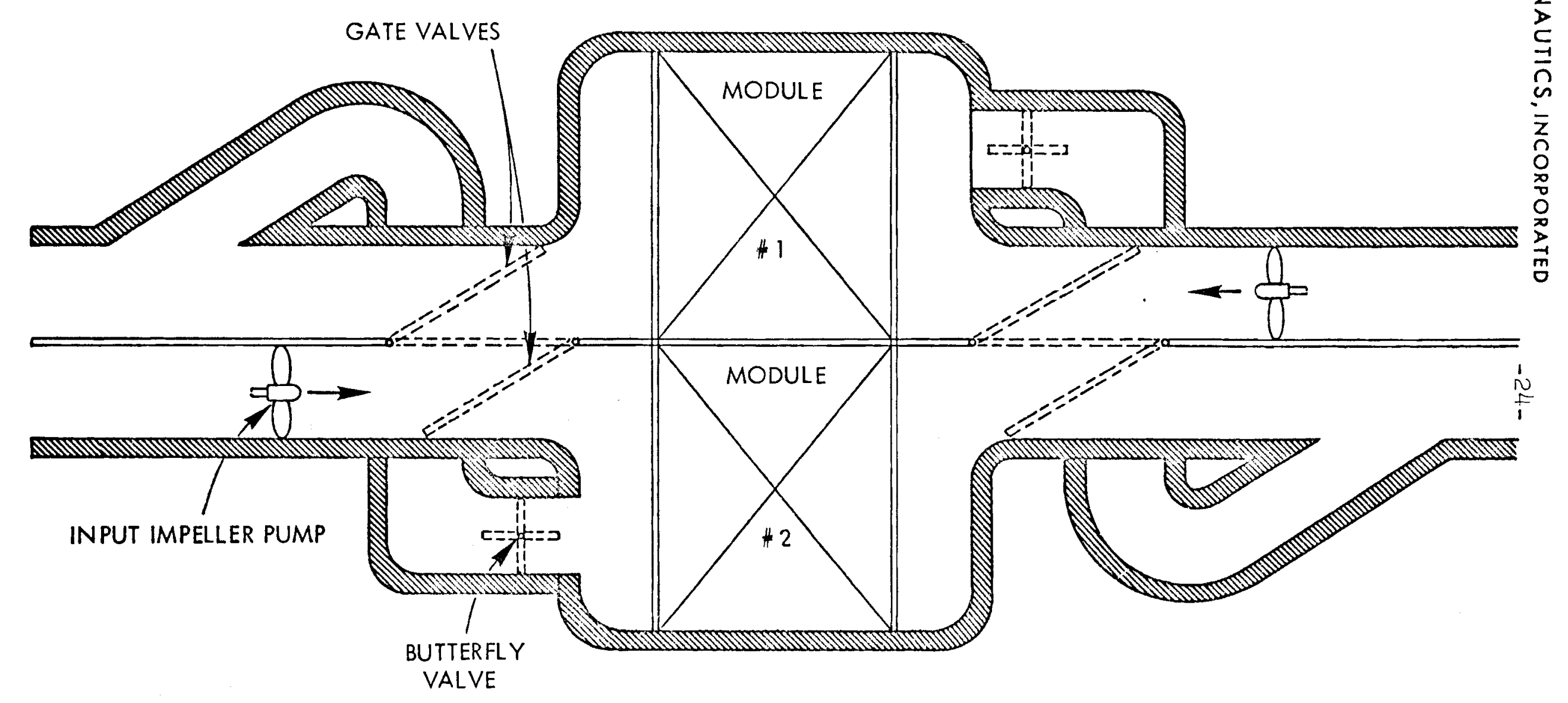

a) Showing the components of this concept

FIGURE 3 - FLOW DRIVEN BRUSHES: Using the M.A.N. system, with flow reversal by redirecting the opposing flow in subdivided sections of the heat exchanger. 
HYDRONAUTICS, Incorporated

opposite directions, driven by separate impeller pumps (Figure $3 \mathrm{~b})$. In this noncleaning mode the configuration of each submodule half is similar to that in a conventional power plant design. To initiate the cleaning cycle, Figure $3 \mathrm{c}$, power to the impellers would be momentarily cut while gate-like valves redirect the inlet water from each half into what had formerly been the outlet water box of the adjacent half. Concurrently, a butterfly valve would be opened to complete the bypass circuit. The remaining momentum in the flow after the power to the impeller is cut will still be large, and a design study would be required to determine whether the gates can be built to withstand the water-hammer loads and to allow rapid flow reversal with a negligible loss in heat transfer. The flow reversal may be maintained for the required period (probably less than 30 seconds) before returning to the normal flow patterns. The cleaning frequency which will be required in OTEC is unknown; however, in commercial power plants the M.A.N. system maintains the desired heat transfer with cleaning cycles of once every eight hours.

An alternative adaptation illustrated schematically in Figure 4a ("unfolded" view) proposes the subdivision of each 25 megawatt unit into an even number of smaller heat exchanger submodules (six for example). Each submodule would have an impeller pump with variable pitch (reversible) blades. Pairs of adjacent heat exchangers could be isolated for inspection, repairs, or to apply other forms of cleaning. To initiate the cleaning cycle it would be necessary to reverse one of each pair of impeller blades and possibly reduce both flows to half their 


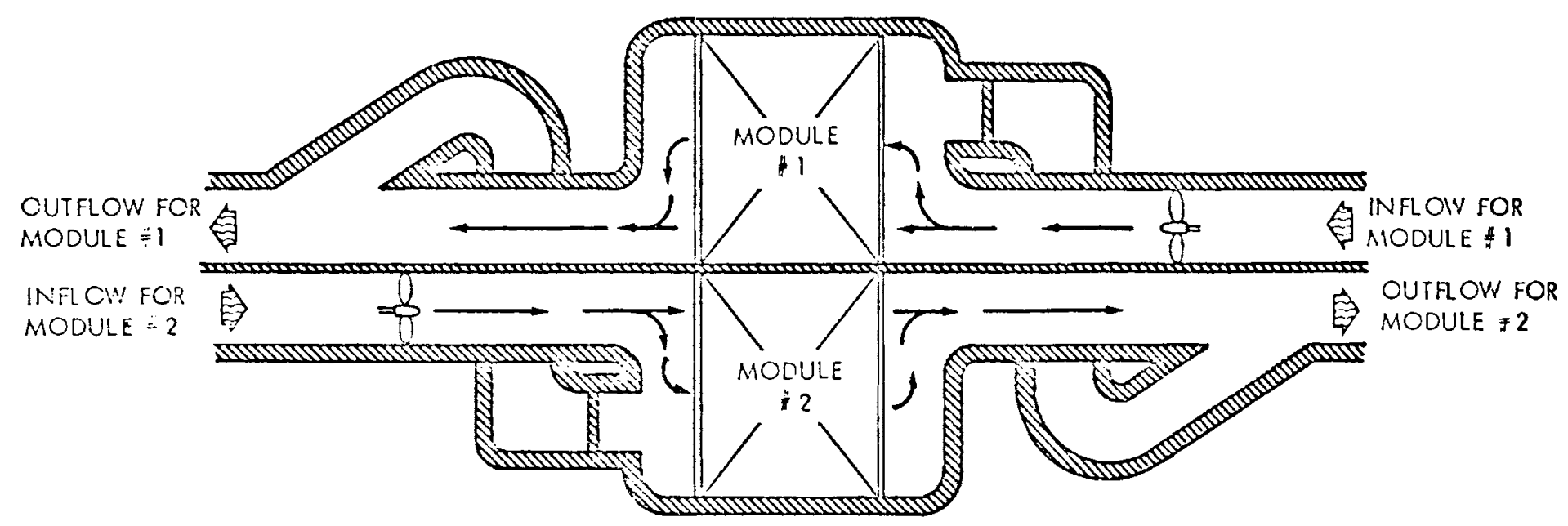

b) Flow patterns during normal operation

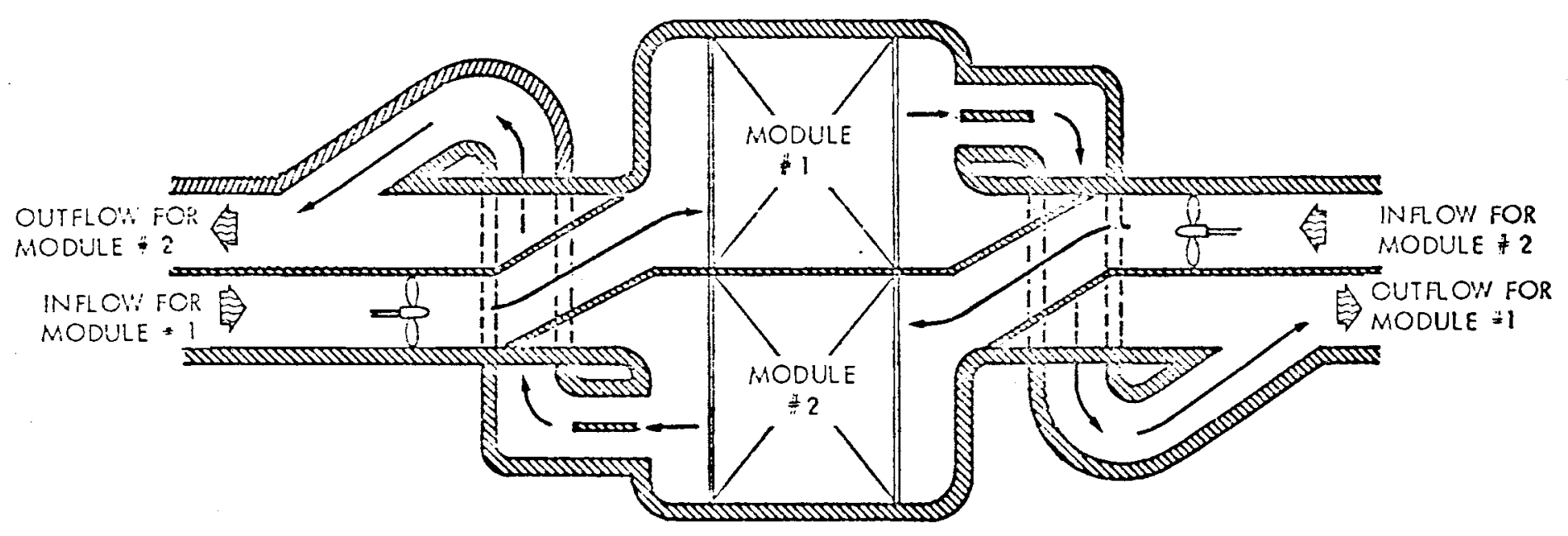

c) Flow reversal patterns during cleaning operation

FIGURE 3 - CONTINUED 


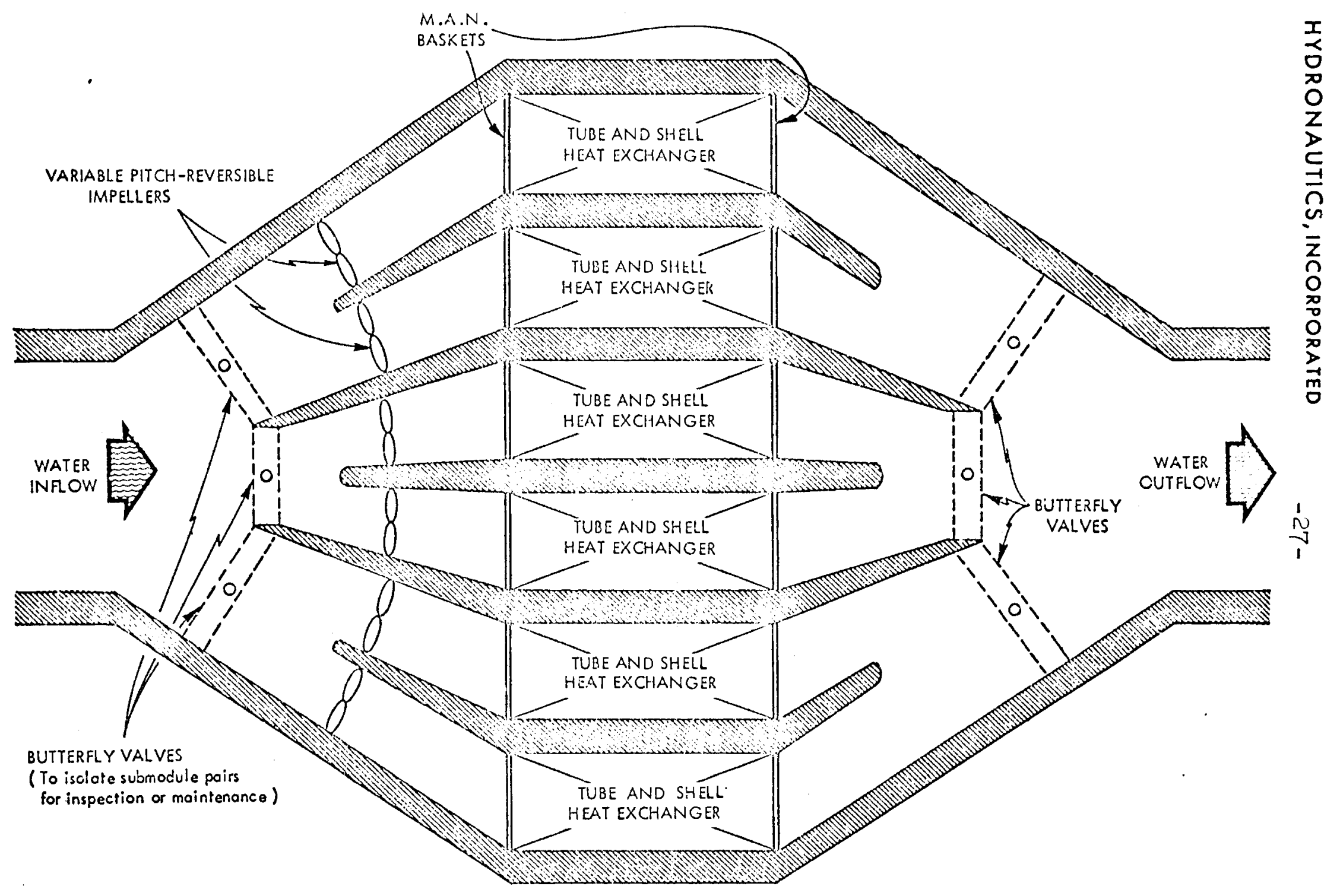

FIGURE a) Showing the components of this concept

FIGURE 4 - FLOW DRIVEN BRUSHES: Using the M.A.N. system, with flow reversal within adjacent pairs of heat exchanger submodules 
HYDRONAUTICS, Incorporated

capacity (to avoid doubling the volume flow in the uncleaned unit), as indicated in Figure 4c. In this manner, the brushes in every other submodule would be driven through those tubes, and then returned to the downstream baskets when the flow is returned to the normal direction (Figure 4b). Note that the geometry of this concept would allow recirculation around adjacent submodule pairs without the requirement for closing of the butterfly valves (the actual geometric configuration would obviously be more compact than the "unfolded" view in Figure 4a). The above system will present several problems including the increased costs for variable pitch impellers, the complex ducting for the submodules, and the increased pressure drops due to compounding of the flows in one of each submodule pair. The modularization however, may permit more flexibility in routine maintenance. Generally, the advantages of the M.A.N. system are a variable cleaning frequency which could be optimized by plant operators, a long-life cycle (5 years) for the cleaning elements. In addition to flow reversal, the disadvantages include loss of the temperature increment across heat exchangers which are being cleaned, undetermined erosive and/or corrosive effects of the brushes on aluminum and the possible need for some form of control of the working fluid flow so as to maintain a balance with the flow of the cooling (or heating) water. The relative advantages and disadvantages of the concepts shown in Figures 3 and 4 would have to be critically assessed technically and economically.

Chlorination - As discussed in detail in Reference 1, the chlorination of cooling water has been practiced in three forms: 


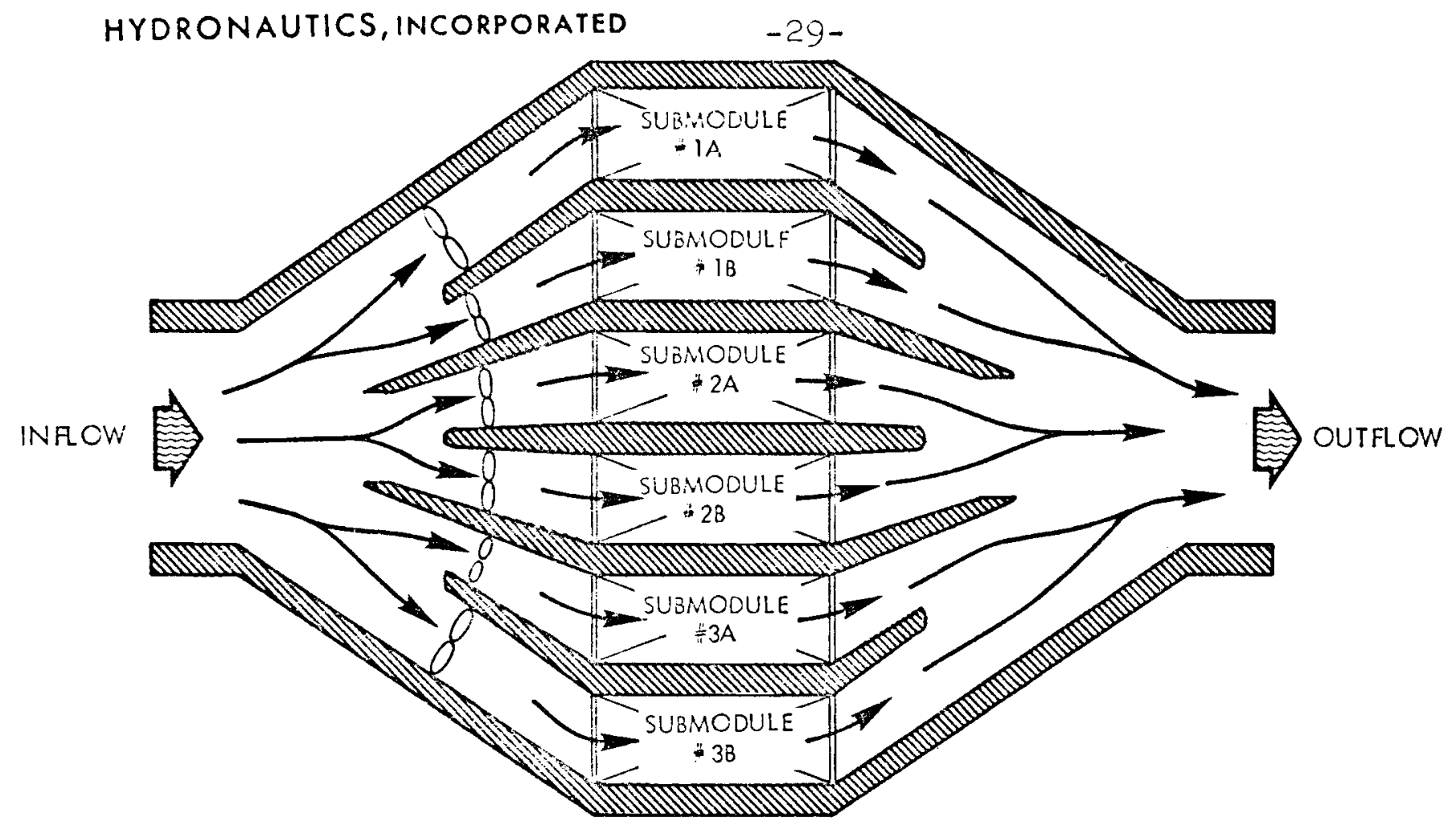

b) Flow patterns during normal operation

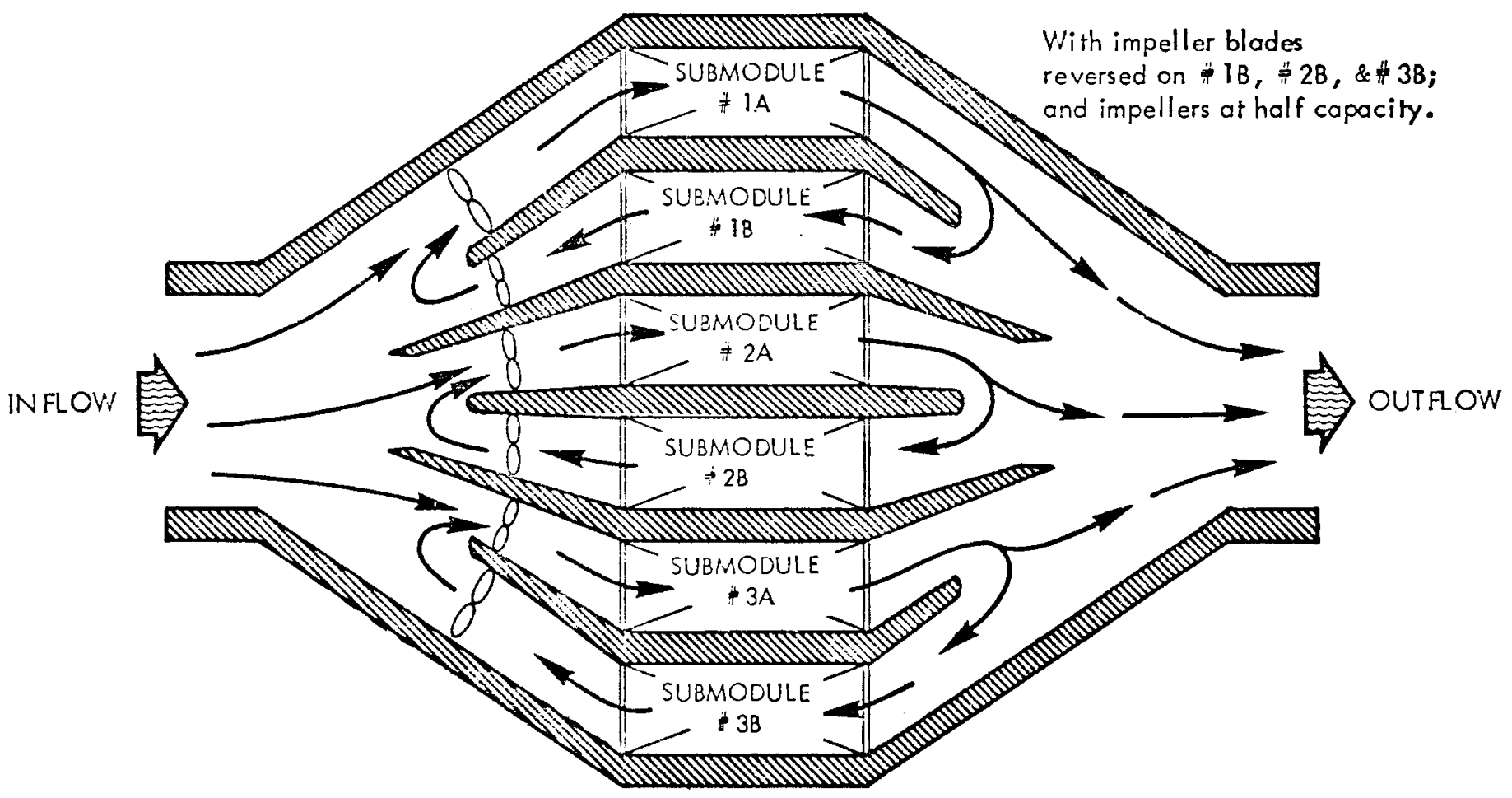

c) Flow patterns during the cleaning opcration: with flow reversal in one of each pair of submodules 
HYDRONAUTICS, Incorporated

$$
-30-
$$

gaseous chlorine, commercial sodium hypochlorite solutions, or electrolytic on-site hypochlorite generation. Of these three, the on-site generation of hypochlorite is considered to be the most practical and economical water treatment method.

As shown in Figure 5, sodium hypochlorite can be generated electrolytically from seawater. It can be applied continuously in low concentrations, or intermittently as a shock treatment where higher concentrations are required. To increase the concentration of the injected solution, a recirculation capability can be incorporated into the generating system. Hydrogen is formed as a co-product of the electrolytic process and, if it can be coliected and purified, this could offset a part of the porer costs of the system.

Sodium hypochlorite can be introduced into the system at various points. If inlet conduit fouling control is desired, it may be possible to introduce it in the inlet conduit boundary layer where its effect will be maximized. To achieve fouling control within the heat exchangers, the hypochlorite solution should be injected in front of the inlet tube sheet. A recent General Dynamics patent (16) provides a novel injection concept, whereby the electrodes constitute a part of the inlet tube sheet and the $\mathrm{NaOCl}$ is thus formed at the tube inlet. However, further experience is needed before the system can be adequately evaluated. It is necessary to demonstrate that fouling at the tube sheet cathode will be prevented by the turbulence caused by the electrodes. Also, current reversal could introduce slectrolytic corrosion problems whenever the tube sheet cathode is acting as an anode. An additional problem may be the periodic replacement 


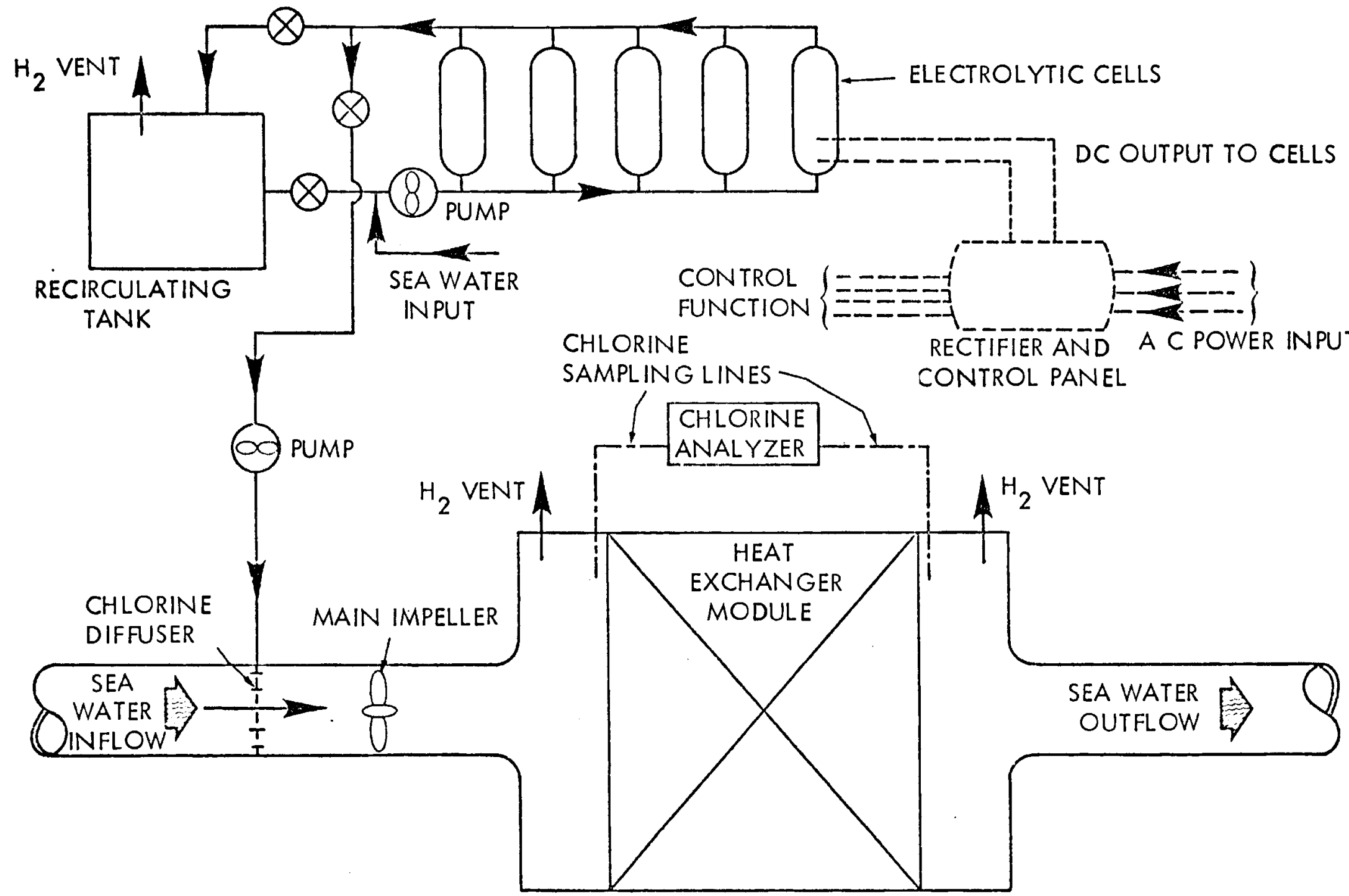

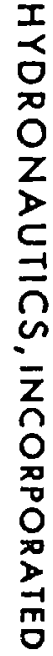

FIGURE 5 - A WATER TREATMENT SYSTEM USING ONSITE ELECTROLYTIC GENERATION OF SODIUM HYPOCHLORITE 
HYDRONAUTICS, Incorporated

of those more complex electrodes. This process confines the chlorine activity to the heat exchanger tubes only but it appears to be less power efficient than existing hypochlorite generation cells. The conventional hypochlorination systems, which provide more versatility and are backed by commercial experience, may therefore continue to be preferred.

The optimum concentration of $\mathrm{NaOCI}$ required for biofouling and especially microfouling control remains relatively unexplored despite many years of commercial experience. Concentrations ranging from $0.2 \mathrm{ppm}$ to several parts per million have been used in continuous and shock treatment methods. "Exomotive" concentrations as low as $0.02 \mathrm{ppm}$ have also been reported effective for macrofouling control, but inadequate existing control techniques would make this of limited value for OTEC. Furthermore, the so-called "cleaning" effects of NaOCl have not yet been established. Thus, the ability of chlorination alone to maintain OTEC heat exchanger cleanliness is unknown at this time.

In summary, the advantages of this technique include: versatile application modes and levels of treatment; the on-line nature of the method; and the state-of-the-art status of all components. Some of the disadvantages are: possible degrading effects if used with aluminum or plastics; ineffectiveness against any type of fouling deposits other than those of biological nature; questionable ability to remove attached fouling; and adverse environmental effects and high costs if used at high concentrations. 
HYDRONAUTICS, Incorporated

Combinations of Cleaning Methods - Although electrolytic hypochlorination, the M.A.N. system or the Amertap system may individually be sufficient to maintain the cleanliness of the seawater side of the tube and shell designs under OTEC conditions, their viability cannot be assured without field experience. Furthermore, conditions may be foreseen where either water treatment or mechanical cleaning alone would not be adequate for maintaining the OTEC design heat transfer coefficients. The conventional power industry, which often encounters very severe biofouling problems, customarily utilizes a combination of various techniques.

Calcareous deposits, or corrosion products, if formed on the condenser walls, will not be removed by chlorination. Likewise, it is conceivable that a very thin but active biological layer can exist despite the use of brushes or sponge rubber balls, in which case a chemical treatment would be required. Also, seasonal changes in the population of fouling organisms or a perturbation of the local biosphere by OTEC related shipping arid/or pollutants may aggravate the biofouling problem after a certain period of operation, when an "island effect" is established. Thus, if economically feasible, a capability for both mechanical cleaning and chlorination is recommended at least for the first generation of OTEC plants.

B. Fouling Control in Internally Enhanced Tubes with Seawater Inside

There is relatively limited experience in operating internally enhanced tubular surfaces in contact with seawater. 
HYDRONAUTICS, Incorporated

Even less experience and performance data exist for suitable cleaning techniques. As shown in Table 1 , only three methods are considered potentially suitable for this type of heat exchanger, namely: flow-driven brushes, chlorination, and chemical cleaning. Several of the other methods such as ozonation (Figure 6) and/or ultraviolet water treatment (Figure 7) would require considerable R\&D before their acceptability for OTEC could be assessed. Each of these have proven to be an effective water treatment method; however, the conditions to be encountered within an OTEC plant are so dissimilar that it is unlikely that, without major improvements, either can be economically adapted for this application. Debris screening, as discussed in section II is recommended for all types of heat exchangers in conjunction with all of the cleaning methods.

The M.A.N. flow-driven brush system has been used on tubes with internal surface enhancement and on tubes with an oval cross section. However, as no data on their performance with these non-standard configurations are available, their effectiveness is unknown. Based on their configuration, the i.A.N. brushes are compatible with tubes having shallow, sub-boundary layer flutes. As a result of the boundary layer thickness distribution across the fluted surface, the greatest amount of fouling material will accumulate in the bottoms of the troughs where the shear stresses are the weakest. Since the brush bristles will naturally seek the grooves or troughs, these areas will be cleaned the best if the bristle density is high enough. The conceptual designs proposed for smooth bore tubes (Section III.A) apply equally well to the enhanced surface tube and shell 


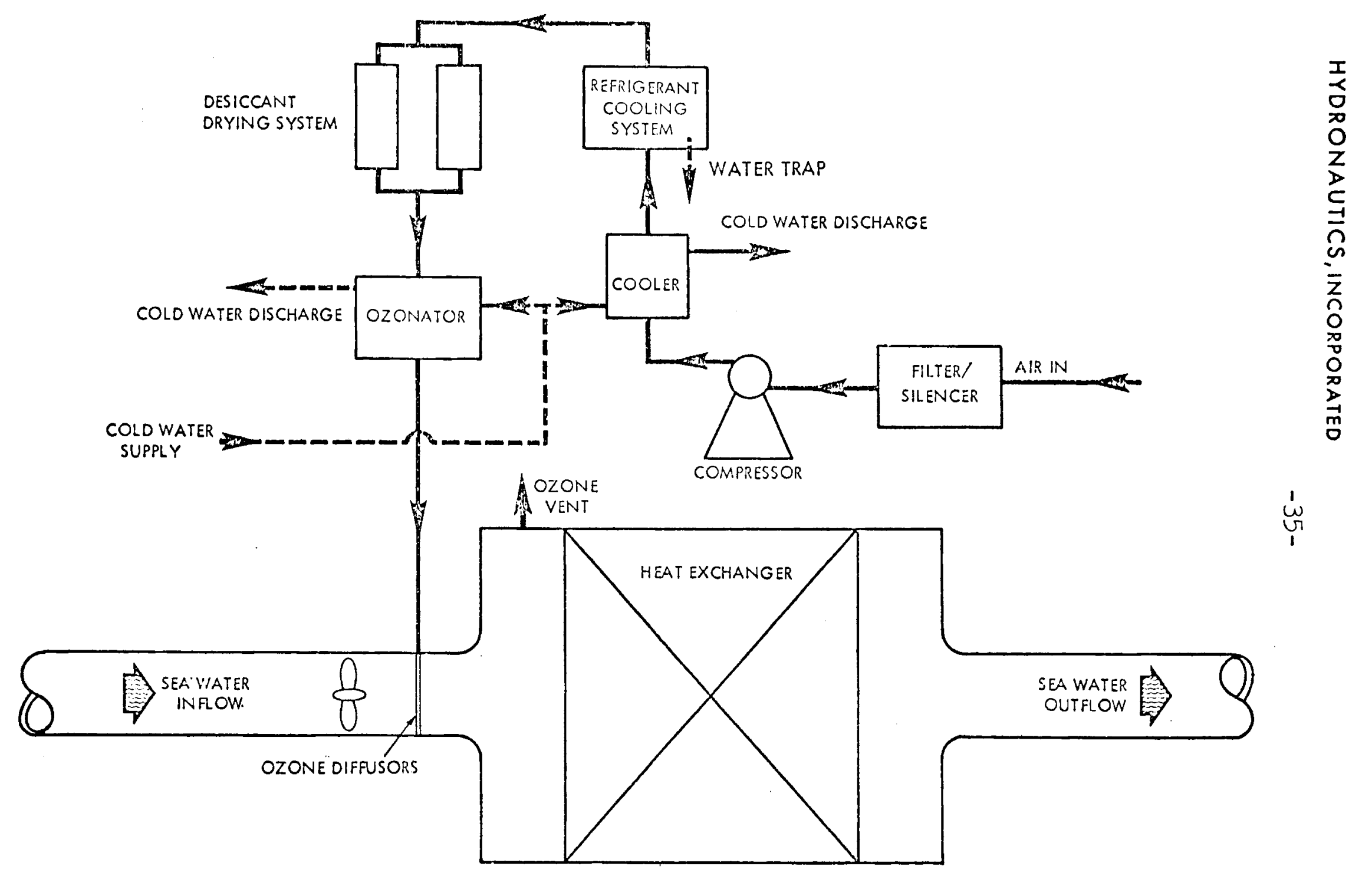

FIGURE 6 - AN OZONE WATER TREATMENT SYSTEM 


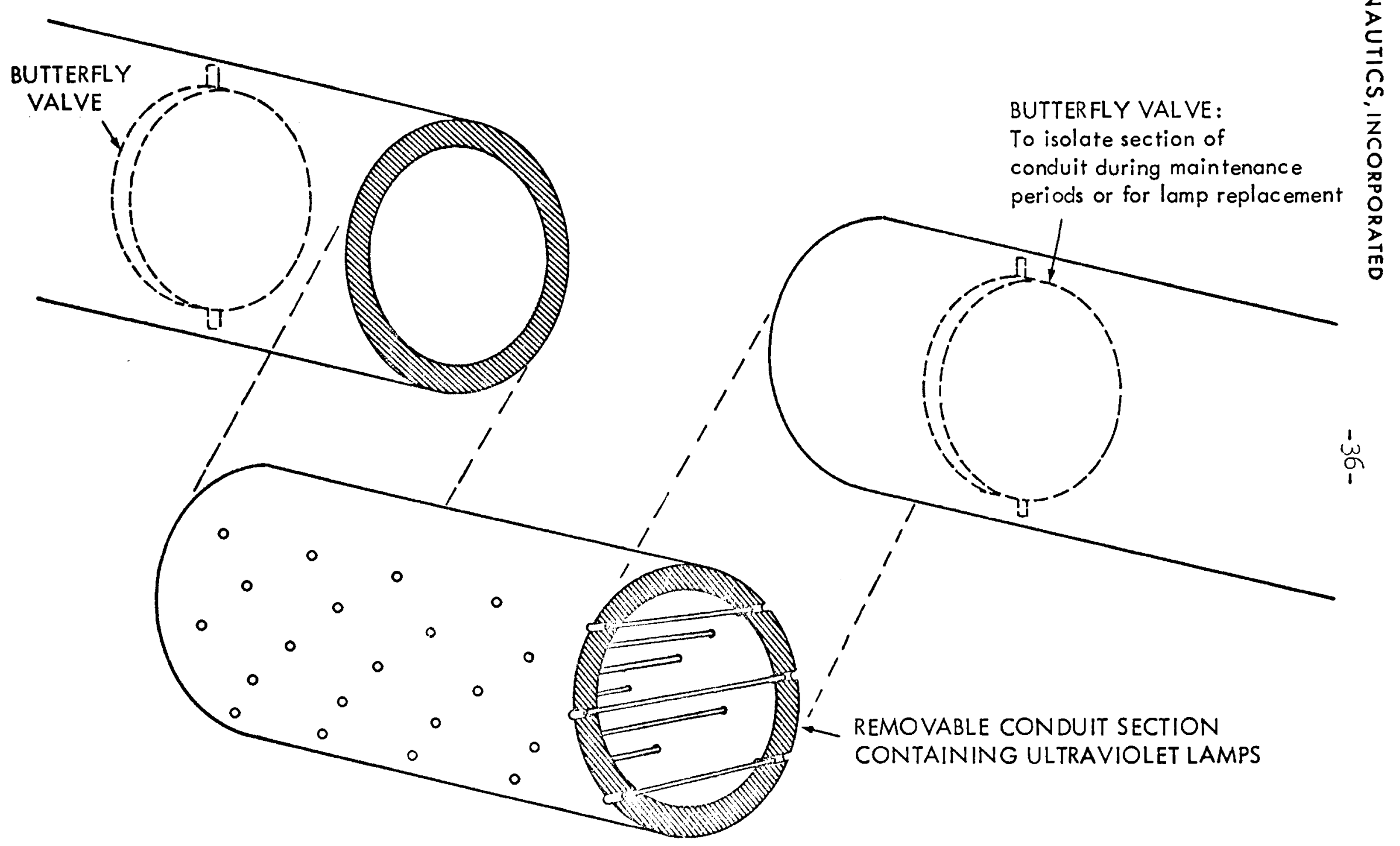

FIGURE 7 - ULTRAVIOLET WATER TREATMENT: An array of lamps in a removable section of the inl et conduct. 
HYDRONAUTICS, Incorporated

designs. One modification would be in the press fit between the M.A.N. baskets and the tubes which would have to be designed to accommodate the internal fluting. The advantages and disadvantages of the M.A.N. system are discussed in Section III.A.

Chlorination and chemical cleaning were discussed in Sections III.A and II, respectively. Since these methods are relatively independent of the heat exchanger geometry, the above referenced discussions apply to enhanced surfaces as well. Slightly higher concentrations of hypochlorite may be required to accommodate the larger surface area of an enhanced tube; however, the total amount of hyochlorite should not change significantly since the water volume would be reduced.

As discussed earlier, the use of slurries has not been tested or documented sufficiently to allow a definitive assessment of the method. However, it seems that the application of slurry cleaning to enhanced tubular surfaces may lead to accumulations of particulate materials in flutes or grooves where water stagnation might be encountered. The potential of slurry cleaning, however, seems promising enough to warrant further research.

A combination of low-level, continuous chlorination as a preventive measure, with intermittent slurry cleaning may constitute an adequate fouling control system for a future OTEC plant with internally enhanced tubes, provided an appropriate slurry material can be identified, and no clogging problems are encountered. 
HYDRONAUTICS, Incorporated

If low intensity ultrasound can be proven effective in the inhibition or retardation of microfouling (as has been shown for macrofouling, see section II), it may become a valuable preventive treatment technique. Although the method may be utilized for most of the heat exchanger designs, it would be more attractive for the ones with enhanced surfaces which cannot be treated with the more conventional techniques. Moreover, since these heat-exchangers will probably require shorter tubes, shorter ultrasound propagation distances will be required. Figure 8 illustrates a suggested arrangement wherein ultrasonic transducers will be affixed to the tube sheets which will transfer the energy to the heat exchanger tubes.

The Amertap sponge-rubber balls, in their current round shape, are clearly not applicable if the fluting or fins are relatively large, since the balls would tend to bridge the gaps between the protrusions. Furthermore, the Amertap balls, unlike the M.A.N. brushes, will exert a greater cleaning shear on the tops of flutes where the biofouling is expected to be the lowest. Thus, the use of Amertap talls for cleaning tubes with enhanced surfaces is not considered feasible unless new types of balls (e.g., textured, or bristled) are developed.

In summary, the cleaning of internally enhanced tubes might be accomplished through a combination of mechanical cleaning and chemical water treatment. The only systems that appear promising in their state-of-the-art form are hypochlorination (on-site generation), and the M.A.N. flow-driven brushes. However, field studies are needed to substantiate the applicability of these 


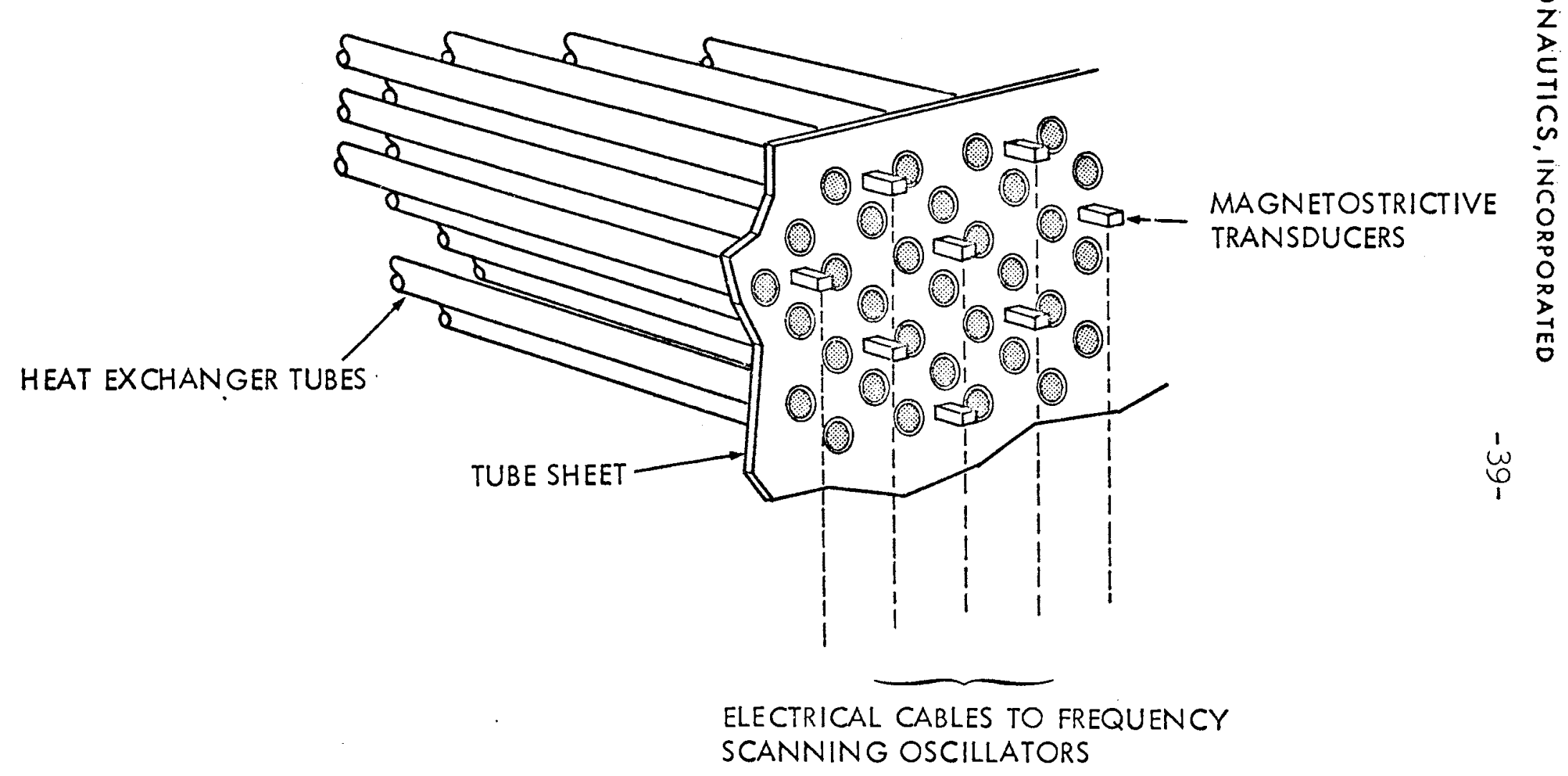

FIGURE 8 - ULTRASONIC BIOFOULING PREVENTION: With ul trasound transmitted to the tubes by vibration of the tube sheet. 
HYDRONAUTICS, Incorporated

$$
-40-
$$

fouling control concepts before the value of enhanced surface tubes for heat exchangers can be established. Further research in key areas, as discussed in Section IV may yield other improved techniques.

C. Fouling Control in Large Diameter Tubes with Seawater Out-

No cleaning method in its current, state-of-the-art design can be directly applied to the cleaning of the trombone heat exchanger design. As discussed in earlier sections, water treatment techniques are applicable to all closed cycle designs. However, the ability of these techniques to remove slimes that are attached to a surface is not clearly established. The only cleaning methods with some promise for use in the trombone heat exchanger design are chemical cleaning, slurries, water jet cleaning and mechanical cleaning (20).

Chemical Cleaning - A conceptual system for chemical cleaning was discussed in Section II. Two types of chemical cleaning configurations which might be used in an OTEC plant are shown in Figures 9 and 10. The concept in Figure 9 suggests recirculation of the solutions and recovery of the chemicals by means of a settling tank where the fouling materials removed from the heat exchangers will be separated and discarded.

The foaming technique as illustrated in Figure 10 may be particularly applicable to the trombone design. A system employing foam as the chemical washing agent has the advantage of occupying a smaller storage volume at the added cost of foaming and defoaming equipment. In many cases acidic cleaning of heat 
HYDRONAUTICS, INCORPORATED

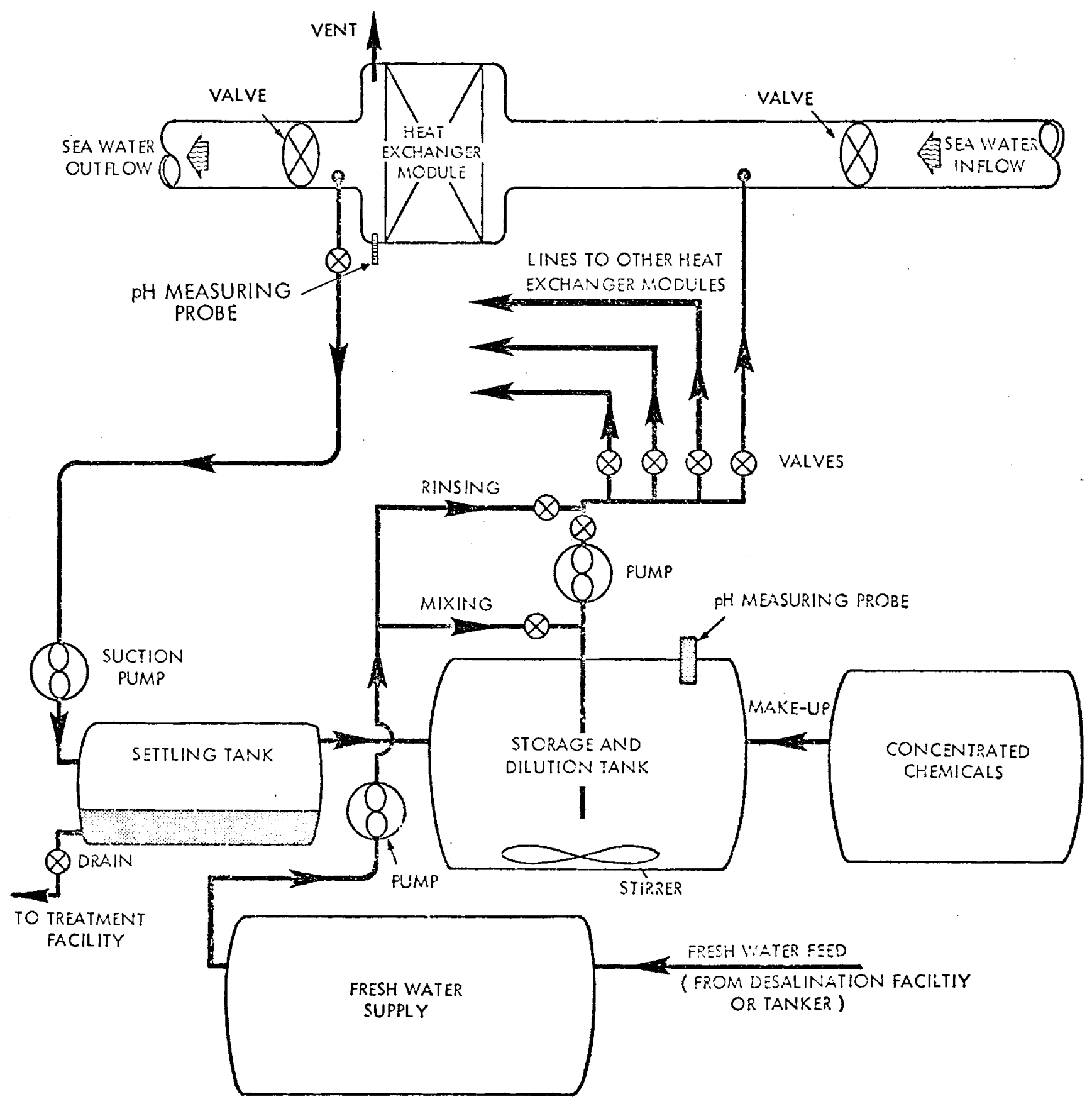

FIGURE 9 - A CHEMICAL CLEANING SYSTEM WITH RECIRCULATION CAPABILITY 


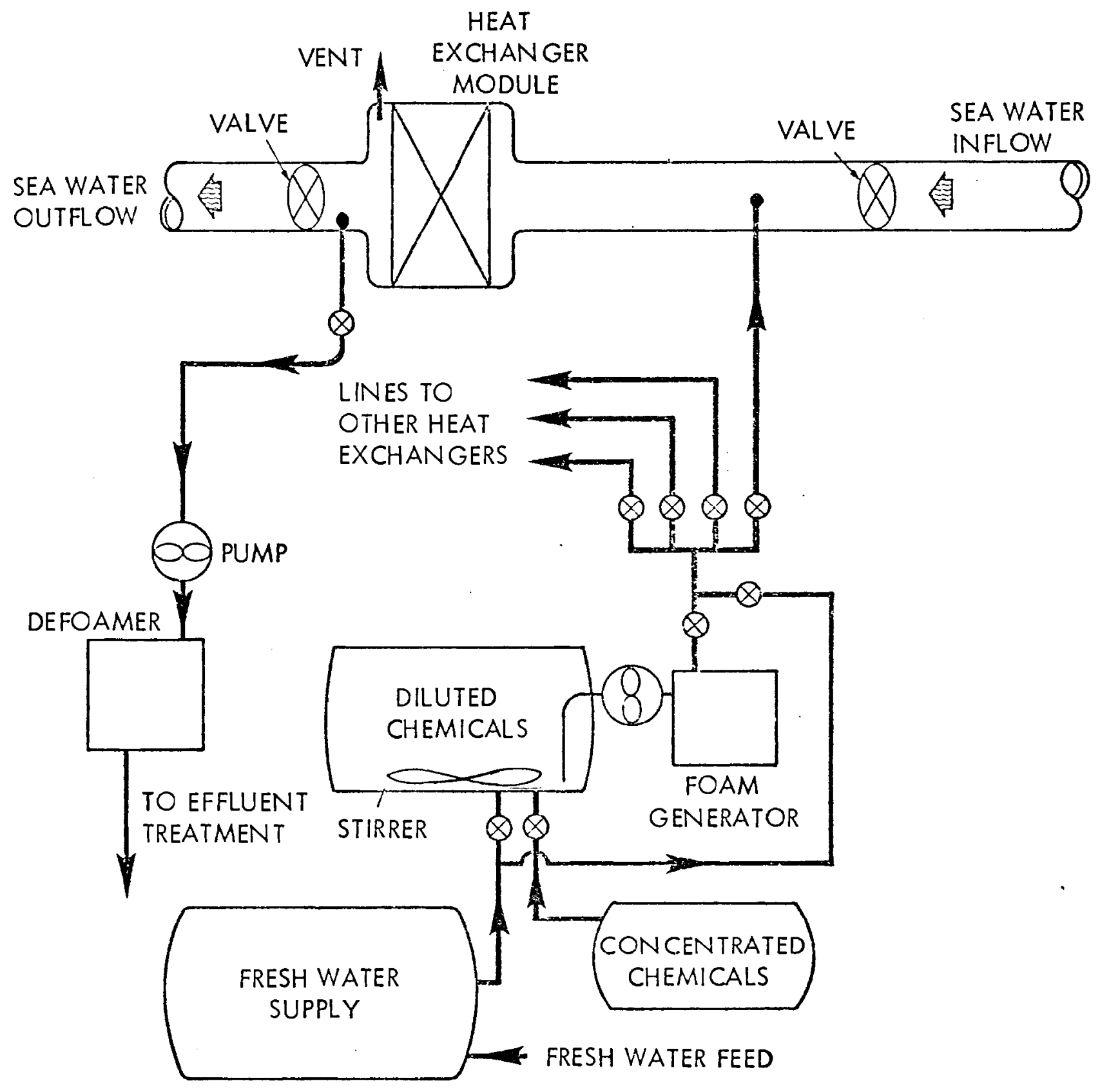

FIGURE 10 - A ONCE-THROUGH FOAMED CHEMICAL CLEANING SYSTEM 
HYDRONAUTICS, Incorporated

exchangers could be hazardous due to the accumulation of hydrogen which is formed as a reaction product, however, the fact that the seawater side of the trombone design is vented to the atmosphere alleviates this problem. Disadvantages may be related to the following unanswered questions:

a. What is the minimum down-time required for a full cleaning cycle?

b. Will foam cleaning alone, without additional mechanical "scrubbing," remove microfoulants to the extent required for effective OTEC operation?

c. Can any of the available cleaning formulas be used frequently with aluminum without causing pitting and leaks?

d. What would be the consequence of possible leaks of cleaning materials into the working fluid side?

e. Will draining of this fluid be required for cleaning?

From the above, it is evident that the technique of foam chemical cleaning requires further research before its viability for the "trombone" design or for OTEC in general can be assessed.

Slurries - The potential and problems for the use of slurries to clean OTEC heat exchangers was discussed in Section II. If and when an appropriate material is indeed identified, which will not damage aluminum, it may have some advantage over 
HYDRONAUTICS, Incorporated

$$
-44-
$$

chemical cleaning. However, accumulation in stagnant areas may prove to be a problem.

Water Jet Cleaning - Water jet cleaning is not practical for most of the proposed OTEC heat exchangers, however, with proper design, water jetting appears to be the most economical method for cleaning "trombone" heat exchangers. Figures lla and llb show a conceptual design, which has been proposed by HYDRONAUTICS, Incorporated for use in the Johns Hopkins Applied Physics Laboratory's baseline concept. A cleaning head with multiple nozzles would be inserted between heat exchanger tubes and guided by a track in the walls of the heat exchanger structure. Water would be supplied through flexible hoses to the cleaning head.

If the CAVIJET ${ }^{\mp M}$ cavitating water jet method ${ }^{*}$ is used, the cleaning action would result from cavitation erosion as well as high velocity fluid shear (17). Since for metals there is a finite time known as the "incubation period," wherein no measurable macroscale damage occurs under exposure to low intensity cavitation, it should be possible to tailor the pump pressure, and hence the jet velocity, so as to avoid damage to the surface of the substrate material. The large difference between the erodibility of the foulants and the substrate should facilitate the empirical selection of the correct operating pressure. With the CAVIJET method, relatively low pressures (less than 1500 psi) are required to remove slime and the net force on heat exchanger tubing due to jet impact is therefore minimized. Furthermore, this method can be operated on-line, causing no interruptions of the heat exchanger operation. Disadvantages include the *A method patented by HYDRONAUTICS, Incorporated. 


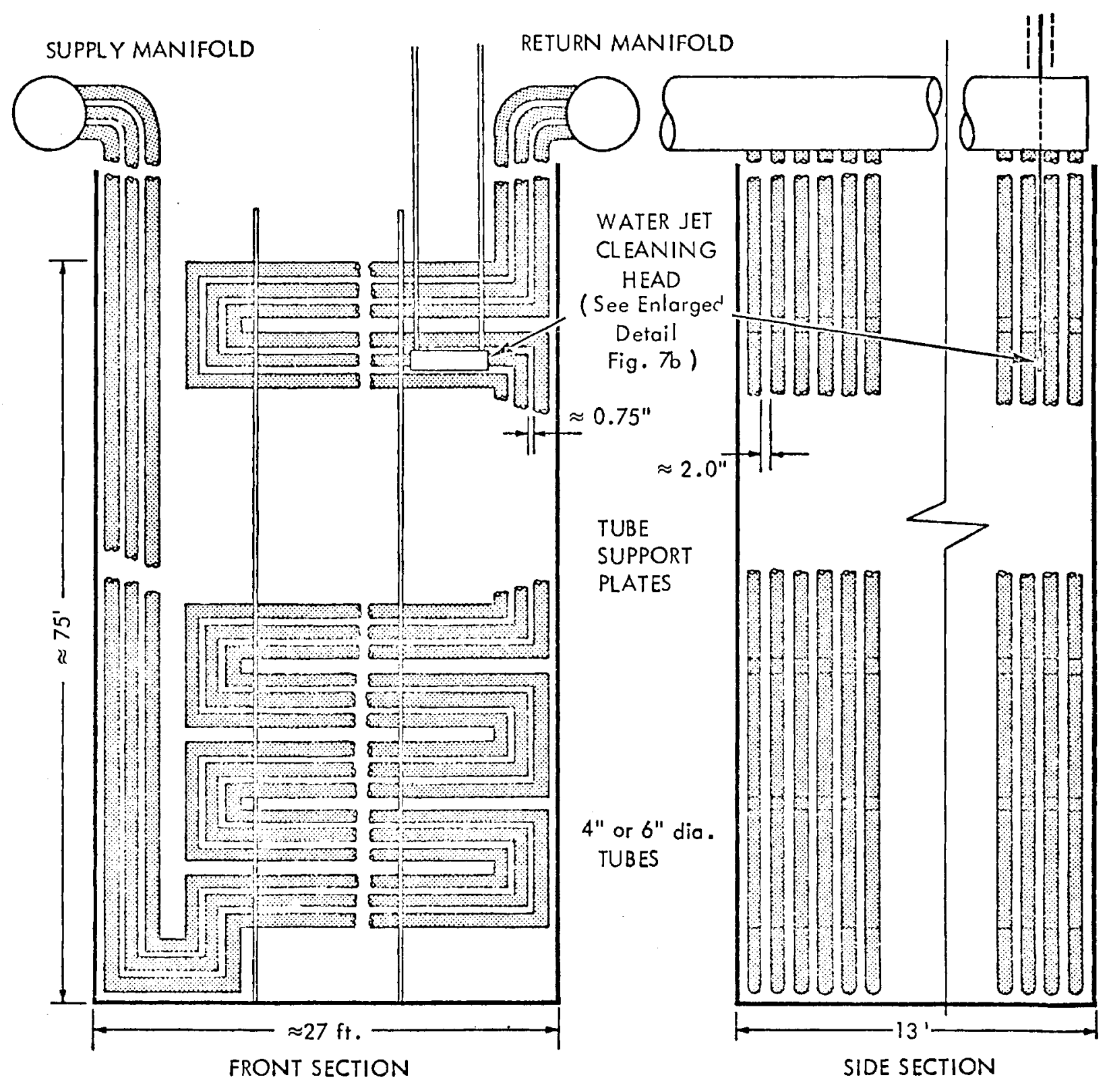

FIGURE $11 a$ - LARGE DIAMETER TUBE AND SHELL HEAT EXCHANGER: The "tromboire" design (after the Applied Physics Laboratory/ John Hopkins University concept) with seawater outside and the working fluid inside the tubes. 
HYDRONAUTICS, INCORPORATED

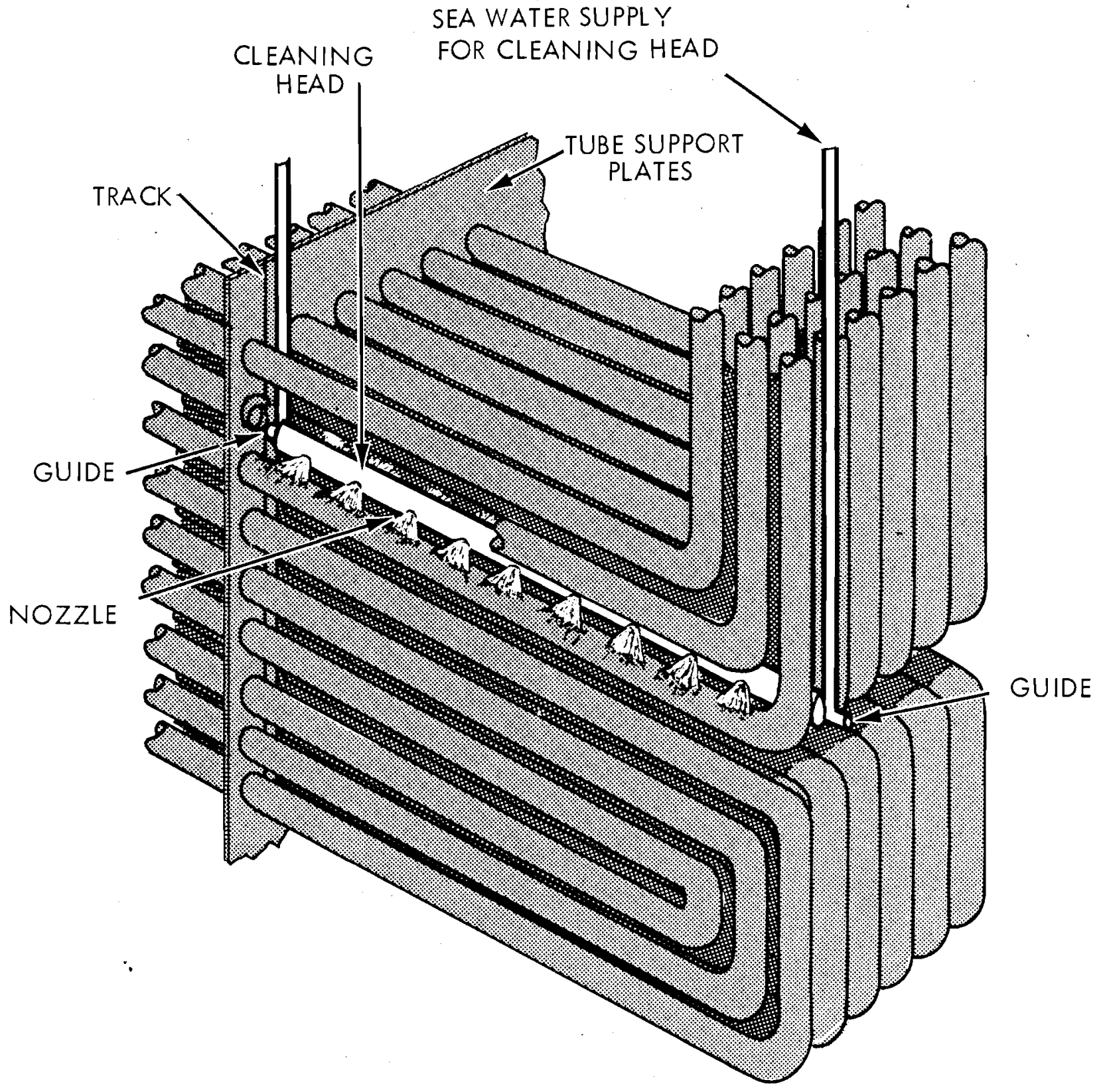

FIGURE 11b - WATER JET CLEANING: Applied to seawater (external) side of "trombone" heat exchanger (after the Applied Physics Laboratory / Johns Hopkins University concept ) 
HYDRONAUTICS, Incorporated

possibility of long-term erosive effects on aluminum and resonance problems. These questions will have to be answered before the value of cavitating water jets can be established.

Another mechanical cleaning method is being examined by A.P.I.* (20), namely the use of arrays of "Scotchbrite" sponges to wipe fouling from the tube walls. From preliminary tests they report that although the sponges provide cleaning along the sides of the tubes which were directly wiped, they were unable to reach the regions between the tubes. Further R\&D is needed to determine whether this method will be practical and economical, and provide sufficient cleanliness.

In summary a mechanical cleaning method, such as water jets or the A.P.I. sponges, appears to be the most cost-effective approach if water treatment at very low chemical concentrations (e.g., less than $0.2 \mathrm{ppm}$ chlorine) is found to be incapable of maintaining the desired cleanliness. The feasibility of adding chemicals to water jets and thereby expediting and improving their cleaning capability may also be worth exploring. As with all heat exchanger designs, there remain key questions that must be answered (see Section IV) before making the final selection of a treatment technique.

D. Fouling Control in Plate-Fin or Extended Surface Heat Exchangers

This heat exchanger design precludes the use of a conventional mechanical heat exchanger cleaning device due to the large number of narrow seawater-side passages. A plate-fin configuration, suggested by the University of Massachusetts at 
HYDRONAUTICS, Incorporated

\section{$-48-$}

Amherst, is shown in Figure 12. This design, which permits considerable heat transfer area in a small space, also typifies the difficult cleaning problem for this type of heat exchanger. If mechanical abrasion is required to maintain heat transfer, the cleaning method for this type of heat exchanger will probably involve some form of abrasive slurry. It may be possible to use a combination of preventive water treatment, such as low-level, continuous chlorination, with intermittent slurry cleaning as required. If sufficiently large particles are employed, a recovery and recycling technique might be used, analogous to the modified Amertap concept described in Section III.A. The use of ferromagnetic slurry particles might allow separation for recycling by the use of a rotating electromagnetic drum. See the discussion in Section II for more information about the potential of slurry cleaning.

Another method for cleaning the uniquely shaped water passages in plate-fin heat exchangers would required special brush configurations and an adaptation of the M.A.N. system (see Section III.A).

If a chemical cleaning method compatible with the selected heat exchanger material can be developed, then either of the chemical cleaning concepts (see Figures 9 and 10) might be used. The advantages and disadvantages of chemical cleaning are covered in Sections II and III.C.

Heat treatment, if effective in fouling removal, might be used, depending upon the final design configuration. In general, plate-fin heat exchangers contain a smaller "at rest" volume of 


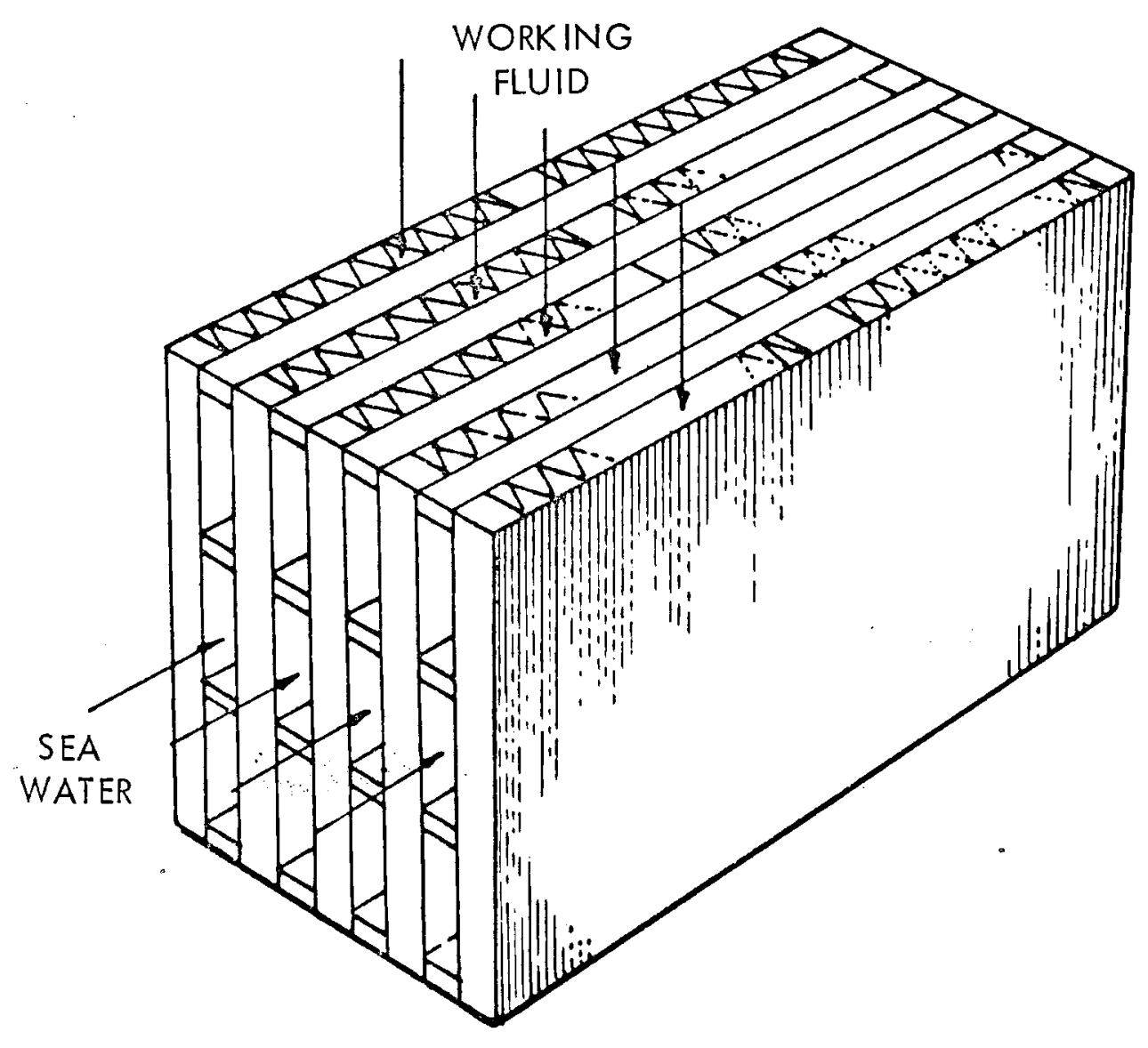

FIGURE 12- A PLATE-FIN HEAT EXCHANGER: The University of Massachusetts-Amherst concept. 
HYDRONAUTICS, Incorporated

water than tube and shell designs. As a result, the power required to periodically raise the temperature to $180^{\circ} \mathrm{F}$ may not be prohibitive if the cleaning frequency is low.

Although little is known about the possible biofouling prevention effects of ultrasonics, the plate-fin design may be compatible with this cleaning method due to its physical configuration. As shown in Figure 12, the seawater and ammonia passages are separated by surfaces that could be ultrasonically excited. The major anticipated problem would be fatigue stresses at the welds or seals between the plates and the extended suraces; considerable R\&D is required to validate this concept. E. Fouling Control in Open-Cycle Designs

The evaporators in the various open cycle designs are perhaps the least likely to suffer the effects of biological foulIng due to the large and rapid pressure reduction inherent in the process, and because much of the surface will be in contact with water which is mainly condensed (or "distilled"). Although bacteria are capable of surviving severe pressure changes, it is cossible that some types would show decreases in their normal attachment and reproductive rates immediately after experiencing such changes. However, nonorganic fouling such as calcareous deposits may be severe on a falling film evaporator.

An important advantage of this system is that the biofouling control problem is not as critical as in the other types of heat exchangers since the fouling does not affect the heat transfer process in the open cycle design. If a cleaning technique is required, automated mechanical brushes or water jets will be 
HYDRONAUTICS, Incorporated

the most effective candidate methods for the flat surfaces of falling film evaporators. Further conceptualizations of cleaning methods must await the baseline designs of these types of evaporators. 
HYDRONAUTICS, Incorporated

IV. CONCLUSIONS AND RECOMMENDATIONS

A. Conclusions

After an in-depth review (1) of existing fouling control techniques, it appears that none of these methods, in their state-of-the-art configuration, can provide adequate as well as economical fouling control for any of the proposed OTEC heat exchanger designs. However, several of the methods may require only minor developmental efforts to achieve satisfactory performance and compatibility with the OTEC requirements. The incorporation of most fouling control techniques into an OTEC system will require significant design modifications of the heat exchanger modules. It appears that further modularization will be a key requirement to allow economical and efficient cleaning.

Effective debris screening is also a prerequisite for the operation of all mechanical cleaning methods as well as for long tube life.

The inclusion of both a fouling prevention method and a stand-by cleaning method, at least for the first experimental generation of OTEC plants, is recommended. Although the initial costs of such dual fouling control systems may be very high, after optimized levels of application are established, this may become practical for production versions of OTEC plants.

Surface treatment methods, although appealing in principle, are at this time neither practical nor sufficiently developed for the first generation of OTEC plants. Although continued research might eventually produce an ideal surface treatment control method, the only conceivable near-horizon concept appears 
HYDRONAUTICS, Incorporated

to be the use of fouling resistant materials for heat exchanger construction.

Water treatment methods permit biofouling control without shutdown or major redesign of the heat exchanger hardware. However, a series of questions regarding practical levels of application, and the effectiveness of the methods in removing attached biofouling, must be studied under OTEC conditions before the viability of each technique can be established. In the current state-of-the-art, low level chlorination appears to be the only immediate candidate.

Among the fouling-removal, or cleaning methods, the ones considered near-term candidates are the Amertap system (recirculating sponge rubber balls), the M.A.N. system (flow-driven brushes) and chemical cleaning.

The several proposed heat exchanger designs will each require different methods of cleaning. Summarized below are specific recommendations for the five design types.

Smooth Bore Tubes, Seawater Inside - For first Eeneration OTEC power plants the installation of a mechanical cleaning method and a chlorination capability is recommended. The mechanical method should be either the Amertap or the M.A.N. system; the choice to be based on side-by-side comparisons under OTEC conditions, and the constraints imposed by the heat exchanger designers. The recommended method for chlorination is on-site sodium hypochlorite generation with provisions for either $0.1 \mathrm{ppm}$ continuous treatment or higher shock concentrations at frequent intervals. The costs for this combined 
HYDRONAUTICS, Incorporated

capability in 1976 dollars can be estimated from Tables 2 and 3. The choice of fouling control methods for the second generation of OTEC heat exchangers would be based upon results from further research and development of the methods as recommended below.

Internally Enhanced Tubes, Seawater Inside - Recommendations for cleaning this type of heat exchanger are somewhat dependent upon the configuration and amplitude of the heat transfer enhancement technique. For instance, a very fine scale enhancement such as a porous surface could not be cleaned by the mechanical wiping of brushes or sponge balls. This type of surface would require some form of chemical cleaning or perhaps a specially adapted ultrasonic treatment. However, for a medium scale enhancement, such as relatively shallow fluting, either the Amertap or M.A.N. systems might be effective. For large amplitude grooves or flutes the M.A.N. system, with brushes specifically designed for the enhancement, or Amertap with a new type of "spiky" textured or bristled balls (possibly soaked in a cleaning solution) would be an appropriate selection. In conjunction with any of the mechanical cleaning sysiems, installation of a sodium hypochlorite generation capability is again recommended.

Large Diameter Tubes, Seawater Outside ("Trombone" Design) The cleaning of this type of heat exchanger cannot be accomplished without developmental work on one of the existing methods. The most promising candidate is water jet cleaning, if it can be demonstrated that the proposed aluminum alloy will not suffer erosive or corrosive damage. An extensive developmental effort is required in order to incorporate and automate a water jet 
HYDRONAUTICS, Incorporated

\section{$-55-$}

system for OTEC conditions. Another candidate method is the one proposed by the A.P.I. team involving cleaning by large arrays of scrubbing sponges. Further tests and development are required before the viability of this concept can be established.

Plate-Fin or Extended Surface Design - This class of heat exchangers presents the most difficult configuration for fouling control. The methods that may be suitable are either in the early developmental stages (e.g., ultrasonics or slurry cleaning) or have doubtful performance characteristics with respect to OTEC microfouling which must be studied (e.g., chlorination: does it remove attached fouling?, chemical cleaning: what are the required concentrations?, etc.). The use of fouling resistant materials for heat exchanger construction may provide part of the long-term solution to the fouling problem for this form of heat exchanger.

Open-Cycle Design - Cleaning of this form of heat exchanger can be readily accomplished by mechanical methods. Either brushes or water jets could be automated to clean the large flat surfaces that are involved.

B. Recommendations for Further Research and Development

For each of the more promising water treatment or cleaning methods specific aspects are cited where further research or development work is required to meet OTEC requirements. A merit value on a scale of [1]-[10] is assigned to each research and development recommended, with [10] as the highest rating.

1. Chlorination: Testing to define the required concentration of sodium hypochlorite to control and/or remove 
HYDRONAUTICS, Incorporated

$-56-$

biofouling under OTEC conditions. [10]

2. Ozonation: Testing to define the required concentration of ozone to control and/or remove biofouling under OTEC conditions; study ozone/ultraviolet combinations to determine possible cost savings with this combination; development of new, lower power ozone generation methods under OTEC conditions.

3. Ultrasonic Biofouling Prevention: Testing to determine potential inhibitory effects of low level ultrasound on OTEC microfouling organisms, assess heat transfer enhancement and head losses and determine the costs involved.

[3]

4. Ultraviolet Treatment: Testing to define the intensity/ duration exposure effects of UV on the microbial slimes found in the OTEC environment.

5. Flow-Driven Brushes (M.A.N. System): Testing to define the required cleaning frequency under OTEC conditions, and for compatibility with aluminum; development of M.A.N. brushes for tubes with enhanced internal surfaces and new flow-reversal methods.

[9]

6. Helically Twisted Inserts: Testing to determine the trade-off of head loss against biofouling control and heat transfer enhancement, and to establish the effect on aluminum and copper-nickel. [4]

7. Recirculating Rubber Balls (Amertap System): Testing to determine the relationship between heat transfer resistance and ball usage, and for compatibility with aluminum; development of new ball recovery and recirculation methods, and less costly balls. [9] 
HYDRONAUTICS, Incorporated

$$
-57-
$$

8. Slurry Cleaning: Testing to determine the effectiveness and economics of various slurry materials, and to define their compatibility with the candidate OTEC heat exchanger materials. [2]

9. Water Jet Cleaning: Development of large scale automated systems, capable of rapid deployment, particularly for the "trombone" or open cycle designs; testing to determine relation between heat transfer resistance, water jet exposure, and possible erosive effects.

10. Chemical Cleaning: Determine the effect of various available chemical cleaning agents on new candidate substrate materials (especially Al, CA 706 and AL-6X stainless steel) as a function of cleaning frequency.

11. Use of Fouling Resistant Materials: Determine how resistant are these materials to microfouling. 
HYDRONAUTICS, Incorporated

$-58-$

APPENDIX A

HEAT EXCHANGER DESIGN CONCEPTS

A. Smooth Bore Tubes, Seawater Inside

The smooth tube and shell concept with seawater flowing inside the tubes has been proposed by both Lockheed and TRW in their baseline concepts $(7,8)$. Lockheed suggested tubes with a two-inch O.D. and a 50-foot length. The TRW design uses tubes with a 1.5" O.D. and a 43-foot length. Both organizations have specified titanium pending further investigations of aluminum alloys. The smooth bore design was considered to be state of the art and would require little if any developmental work. Furthermore, both organizations recognized that the Amertap recirculating rubber ball cleaning system could be used on smooth bore tubes in a manner similar to the widespread commercial use of this cleaning system in power plant condensers. The TRW baseline design has four power modules, each containing a single pass condenser and evaporator. Each power module has over 140,000 tubes.

The Lockheed design also has four power modules, hence a total of four condensers and four evaporators. The number of heat exchanger tubes in the Lockheed baseline design totals nearly one million. Both TRW and Lockheed have proposed modifications to the Amertap system to include a synchronous method for injecting and collecting Amertap sponge rubber balls over a limited portion of the overall area of inlet and outlet tube sheets. The advantages anci disadvantages of this "pitch/catch" concept are discussed in Section III. 
HYDRONAUTICS, Incorporated

B. Internally or Externally Enhanced Tubes, Seawater Inside

Tube and shell designs with internal (seawater side) heat transfer enhancement have been proposed $(11,12,13)$ in order to increase heat transfer coefficients and thereby allow reduction of heat exchanger areas. Since a large part of the initial OTEC cost (50-60 percent) is in the heat exchangers, reduction in their area would present an attractive economic benefit. However, it must be remembered that surface enhancement may seriously aggravate the biofouling control problem. Unless suitable cleaning methods can be provided to keep the enhanced surfaces free of fouling the value of this design is questionable. Various seawater side surface enhancement ideas have been proposed: sub-boundary layer sinusoidal fluting (11), helically twisted heat exchanger inserts (12), high flux porous surfaces (13), and tubes with large, fin-type surface enhancements.

The penalty associated with all forms of surface enhancement is the increased head loss across the heat exchanger. A successful form of surface enhancement must achieve economic and/or heat flux improvements which outweigh the penalty imposed by the increased head losses. Although the details of the fluid and thermodynamic phenomena involved are not well understood, the relevant parameters include the prime surface areas, the real surface area, the fluid dynamic boundary layer thickness, the thermodynamic boundary layer thickness, the flute length, the surface roughness, and, if an insert is present, its physical characteristics. 
HYDRONAUTICS, Incorporated

$$
-60
$$

C. Large Diameter Tubes, Seawater Outside ("Trombone" Design)

Large diameter tubes ( 4 " to 6" O.D.) in a "trombone" configuration have been proposed for use in the Johns Hopkins Applied Physics Laboratory concept (14). The working fluid is contained within the tubes while seawater flows over the external surfaces of a relatively closely spaced tube array. The systems proposed for cleaning this arrangement are a series of mechanically translated cleaning heads containing either cavitating water jets or arrays of "Scotchbrite" sponges mounted on flexible holders. The suggested tube material was one of several candidate aluminum alloys. The detailed problems associated with cleaning this "trombone" tube array are reviewed within section III.

D. Plate-Fin or Extended Surface Design

This type of heat exchanger has been proposed in many forms $(9,10)$. Suggested construction materials have ranged from extruded thermoplastics (15) to stainless steel. Although grouped together because of geometric similarity, the variety of materials proposed would each require different recommendations for biofouling control. The University of Massachusetts has proposed a plate-fin concept which has a triangular seawater channel (9). Other plate-fin concepts have been proposed by DSS Engineers (15) and Solar Sea Power, Inc. (10). Of all the proposed OTEC exchanger designs, these present the most challenging biofouling control problems. 
HYDRONAUTICS, Incorporated

$$
-61-
$$

E. Open-Cycle Design

The general concept of an open-cycle OTEC plant involves a "falling-film" evaporator wherein steam is flash-evaporated from water falling over a flat plate at reduced pressures. In this process the biofouling control problem will be much less critical since the heat transfer process is independent of the fouled surfaces and therefore greater amounts of fouling can be tolerated. Also, the rate of biofouling is expected to be relatively low due to the sudden pressure reduction. Furthermore, the flat surfaces and water passages that will be subject to fouling will be easily cleaned with conventional methods due to their simple geome try. 
HYDRONAUTICS, Incorporated

$$
-62-
$$

\section{REFERENCES}

1. Rice, M. S., Hagel, D. and Conn, A. F., "Methods for Cleaning OTEC Heat Exchangers," HYDRONAUTICS, Incorporated Technical Report 7701-1, April 1977.

2. Stupian, G.W., "Potential Fouling of OTEC Heat Echangers by Marine Organisms," The Aerospace Corporation Report Number ATR-77 (9401-02)-1, November 1976.

3. Dexter, S. C., "Microbiological Fouling and Its Control in Coastal Water and the Deep Ocean," Woods Hole Technical Report WHOI-74-64, September 1974.

4. Fetkovich, J.G., Grannemann, G. N., Meier, O. L., and Munchmeyer, F. C., "Fouling and Corrosion Studies in OTECRelated Heat Exchanger Tubes," Progress Report for the period of July 31, 1975 to January 31, 1976, Report UC-64, February 20, 1976.

5. Czikk, A. M., Fenner, G. W., McLaughlin, D. L., and Zawierucha, R., "Ocean Thermal Power Plants Heat Exchangers, Mid Project Progress Report," Proceedings, Third Workshop in Ocean Thermal Energy Conversion, Houston, Texas, May 1975.

6. Fetkovich, J.G., "Biofouling Experiments at Keahole Point, Hawaii," Proceedings of the Fourth Ocean Thermal Energy Conversion Conference, University of New Orleans, March $22-24,1977$.

7. "Ocean Thermal Energy Conversion (OTEC) Power Plant Technical and Economic Feasibility," Lockheed Missiles and Space Co., LMSC-D056566, NSF/RAINI/SE/GI-C937/FR/75/I, 12 April 1975.

8. "Ocean Thermal Energy Conversion, Final Report," TRW Systems Group, NSF Contract No. NSF-C-958, June 1975.

9. Braren, R. and McGowen, J. G., "An Investigation of Heat Exchangers for Ocean Thermal Energy Conversion (OTEC) Systems," University of Massachusetts Report No. NSF/RANN/ SE/GI-34979/TR/75/8, September 1975. 
HYDRONAUTICS, Incorporated

10. Anderson, J. H., "Compact Plate-Fin Heat Exchangers," Proceedings of the Fourth Ocean Thermal Energy Conversion Conference, University of New Orleans, March 22-24, 1977.

11. Rothfus, R. R., "Concurrent Studies of Enhanced Heat Transfer and Materials for Ocean Thermal Exchangers," CarnegieMellon University Progress Report C00/2641-1, Contract EY-76-S-02-2641-1, July 31, 1976.

12. Sephton, H. H., "Performance Improvement for Ocean Thermal Energy Conversion Systems," University of California Proposal No. UCB-Eng-4263, submitted to ERDA, August 1976.

13. Sabin, C. M., Poppendick, H. F., Connelly, D. J., and Meckel, P. T., "Nucleating Vaporization and Extended Surface Heat Transfer at Low Temperature Difference," Geoscience Limited Report GLR-165, May 1965.

14. "An Analysis of the Maritime and Construction Aspects of Ocean Thermal Energy Conversion (OTEC) Plant Ships," Johns Hopkins Applied Physics Laboratory, December 1975.

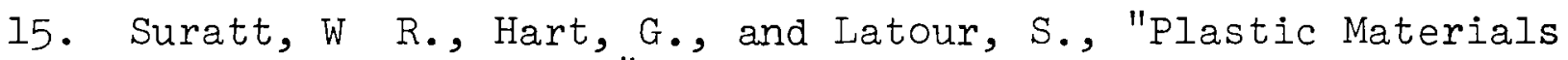
for Heat Exchangers," Proceedings of the Fourth Ocean Thermal Energy Conversion Conference, University of New Orleans, March 22-24, 1977.

16. Freedman, B. J., and Ryskiewich, B. S., "Apparatus for Controlling Marine Fouling of Salt Water Coolant Heat Exhanger Piping Systems," U. S. Patent No. 3,984,302, October 1976.

17. Conn, A. F., Mehta, G. D., and Sundaram, T. R., "Cavitating Water Jets," Proceedings, ASME Cavitation and Polyphase Flow Forum--1976, pp. 12-17, March 1976.

18. Hardin, A. K., "In Pile Defilming of Process Tubes," Report No. HW-40703, January 6, 1976 (available at the Technical Information Files, Pacific Northwest Laboratory, Richland, WA 99352).

19. Ayres, J. A., "Decontamination of Pressurized Water Reactors," Decontamination of Nuclear Reactors and Equipment, J. A. Ayres, ed, Ronald Press, N. Y., pp. 492-493, 1970. 
HYDRONAUTICS, Incorporated

$-64-$

20. Pandolfini, P. P., "Effect of Biofouling and Cleaning on the Heat Transfer at the Exterior of Large Diameter Tubes," Proceedings, OTEC Biofouling Symposium, Seattle, Washington, October 10-12, 1977. 